\title{
Process Development of Sotagliflozin, a Dual Inhibitor of Sodium-Glucose Cotransporter-1/2 for the Treatment of Diabetes
}

Matthew M. Zhao, ${ }^{*}$ Haiming Zhang, ${ }^{\dagger}$ Shinya limura, ${ }^{\ddagger}$ Mark S. Bednarz,, Qiu-Ling Song, ${ }^{\psi}$ Ngiap-Kie Lim, ${ }^{\dagger}$ Jie Yan, ${ }^{t+}$ Wenxue $W u^{*}$

Chemical Development, Lexicon Pharmaceuticals Inc., 110 Allen Road, Basking Ridge, New Jersey 07920, USA

Kuangchu Dai, Xiaodong Gu, Youchu Wang

Process R\&D, WuXi Apptec, 288 Fute Zhong Road, Waigaoqiao Free Trade Zone, Shanghai 200131,

China

mzhao@lexpharma.com; wwu@lexpharma.com

\section{Supporting Information}

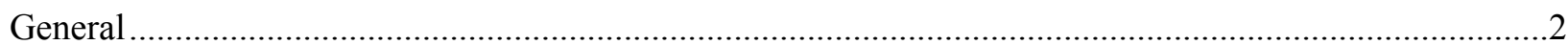

1. $\quad{ }^{1} \mathrm{H},{ }^{13} \mathrm{C}$ NMR Spectra of intermediates and final product...............................................................

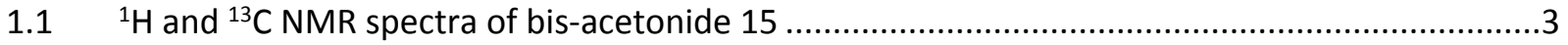

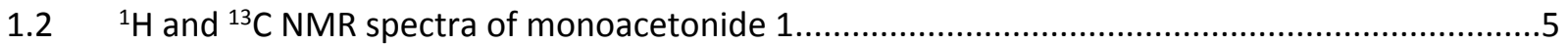

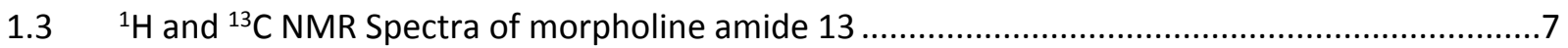

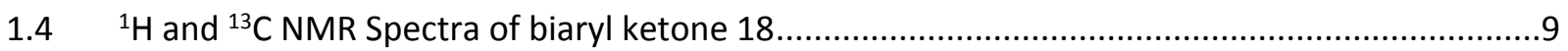

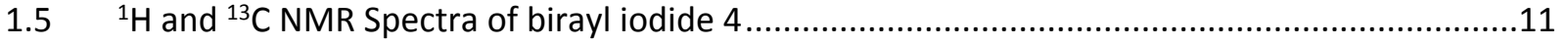

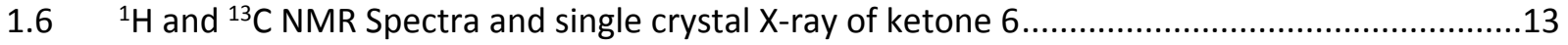

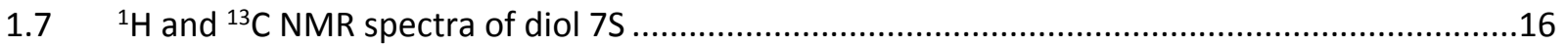

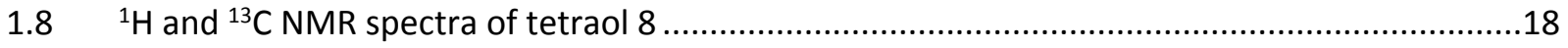

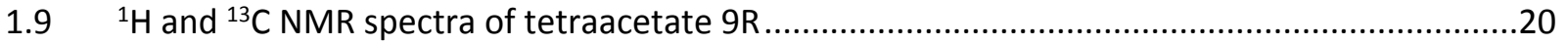

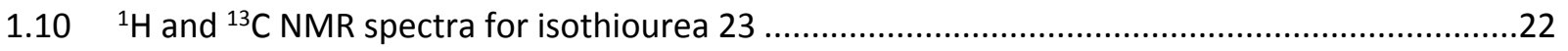

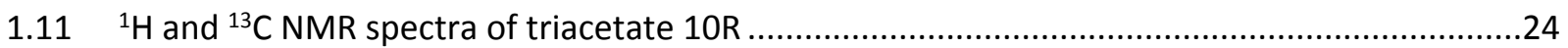

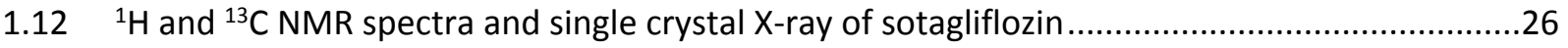

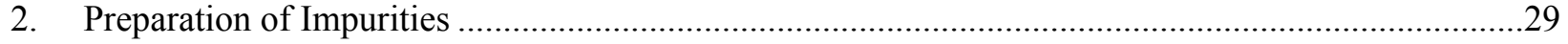




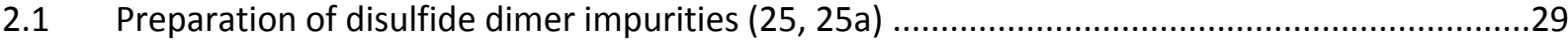

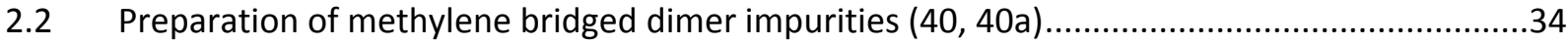




\section{General}

All reagents and materials were used as received, unless otherwise noted. Unless additional GC or GCMS analysis was necessary, reactions were monitored by reverse-phase HPLC (Shimadzu components, UV detection at $220 \mathrm{~nm}$ ), generally using a $\mathrm{C} 18$ or phenyl-hexyl column with water/MeCN or water/MeOH mobile phase and trifluoracetic acid as modifier. Melting point information was collected using a TA Instruments differential scanning calorimeter (endotherm peak temperature). NMR spectra were acquired in deuterated solvents on Bruker AV $400 \mathrm{MHz}\left({ }^{1} \mathrm{H}\right)$ or AV $700 \mathrm{MHz}\left({ }^{1} \mathrm{H}\right)$ spectrometers. Mass spectrometry data were obtained during LCMS analysis (reverse phase Agilent LC / Waters ZQ API-MS with ESCI). Compound purity was assessed by reverse phase HPLC (area percent, UV) and/or by ${ }^{1} \mathrm{H}$ NMR (weight percent assay against an internal standard).

† Small Molecule Process Chemistry, Genentech, Inc., 1 DNA Way, South San Francisco, CA 94080.

$¥$ Japan Pharma Business Unit, Takeda Pharmaceuticals, 1-1, Nihonbashi-Honcho 2-chome, Chuo-ku, Tokyo 1038668, Japan.

$\S$ Abzena Biotechnology, 360 George Patterson Blvd, Suite 101E, Bristol, PA 19007, USA.

${ }^{\Psi}$ Institute of Next Generation Matter Transformation, College of Material Sciences Engineering at Huaqiao University, 668 Jimei Boulevard, Xiamen, Fujian 361021, China.

† Leadart Technologies, Inc. 38 Business Two Road, Suite 1801, Shanglin Innovation Park, Cixi, Zhejiang, China 315300 


\section{1. ${ }^{1} \mathrm{H},{ }^{13} \mathrm{C}$ NMR SPECTRA OF INTERMEDIATES AND FINAL PRODUCT}

$1.1{ }^{1} \mathrm{H}$ and ${ }^{13} \mathrm{C}$ NMR spectra of bis-acetonide $\mathbf{1 5}$

Figure S1. $\quad{ }^{1} \mathrm{H}$ NMR spectrum of bis-acetonide $15\left(\mathrm{DMSO}^{-} \mathrm{d}_{6}\right)$

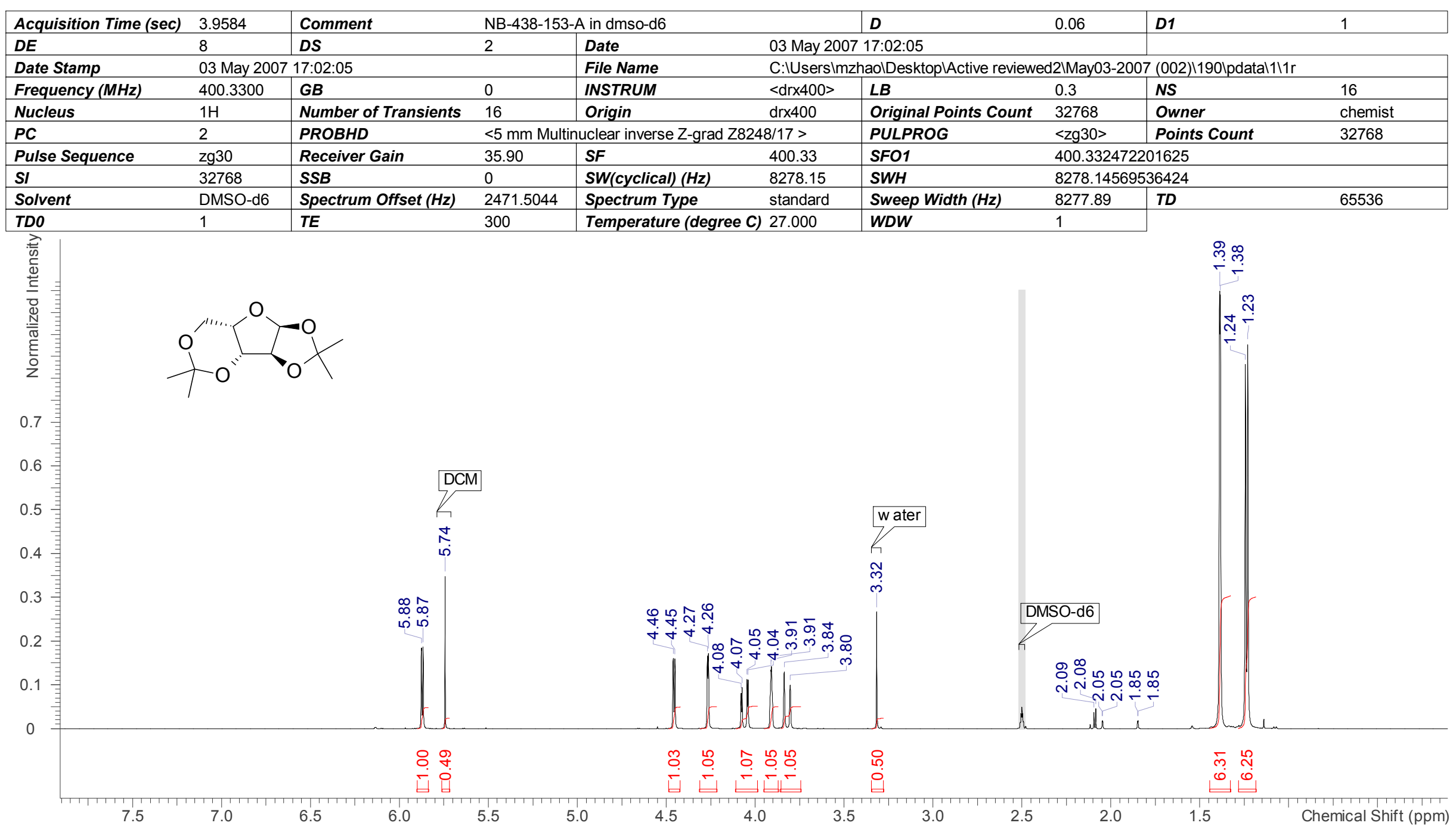


Figure S2. $\quad{ }^{13} \mathrm{C}$ NMR spectrum of bis-acetonide $15\left(\right.$ DMSO- $\left._{6}\right)$

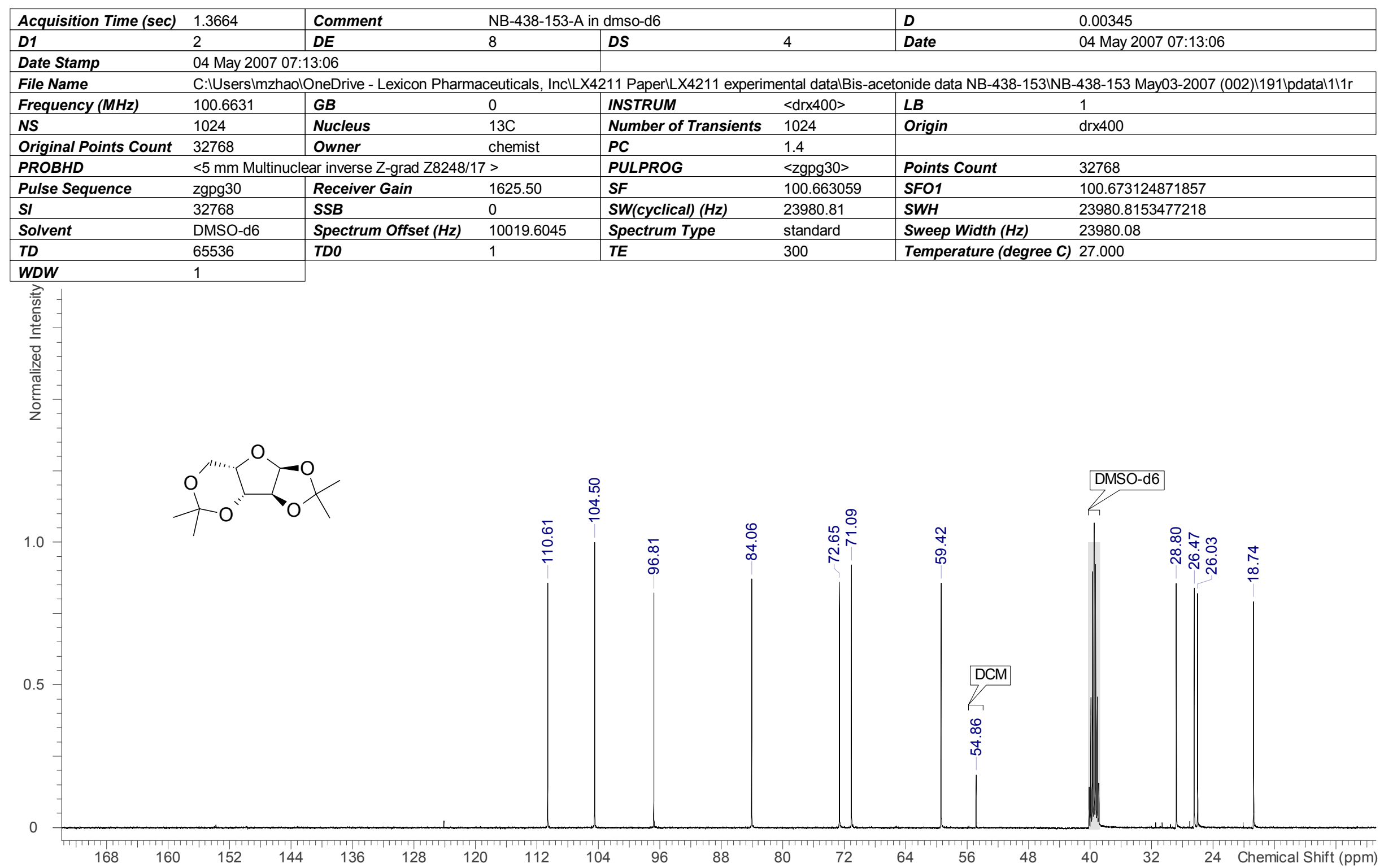


$1.2{ }^{1} \mathrm{H}$ and ${ }^{13} \mathrm{C}$ NMR spectra of monoacetonide 1

Figure S3. $\quad{ }^{1} \mathrm{H}$ NMR spectrum of monoacetonide 1 (DMSO- $\mathrm{d}_{6}$ )

\begin{tabular}{|c|c|c|c|c|c|c|c|}
\hline Acquisition Time (sec) & 3.9584 & Comment & NB-438- & imso-d6 & & Date & 07 May 2007 18:05:52 \\
\hline Date Stamp & 07 May 2 & $5: 52$ & & File Name & Ihw-analyti & ALYTIICAL_INFOUNSTI & TAIDPX40012007IMAY07-2007_140001r \\
\hline Frequency $(\mathrm{MHz})$ & 400.13 & Nucleus & $1 \mathrm{H}$ & Number of Transients & 16 & Origin & dp $\times 400$ \\
\hline Original Points Count & 32768 & Owner & chemist & Points Count & 32768 & Pulse Sequence & 2930 \\
\hline $\begin{array}{l}\text { Receiver Gain } \\
\text { Sweep Width }(\mathrm{Hz})\end{array}$ & 32.00 & SW(cyclical) (Hz) & 8278.15 & Solvent & DMSO-d6 & Spectrum Offset $(\mathrm{Hz})$ & 2470.9668 \\
\hline
\end{tabular}

$\begin{array}{llll}\text { Sweep Width }(\mathrm{Hz}) & 8277.89 & \text { Temperature (degree C) } 27.000\end{array}$

MAY07-2007_140001r VerticalScaleFactor $=1$

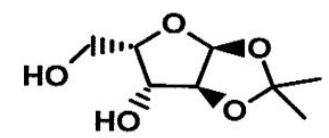

LP-849277-01

NB-438-156-3 in dmso- $d_{6}$

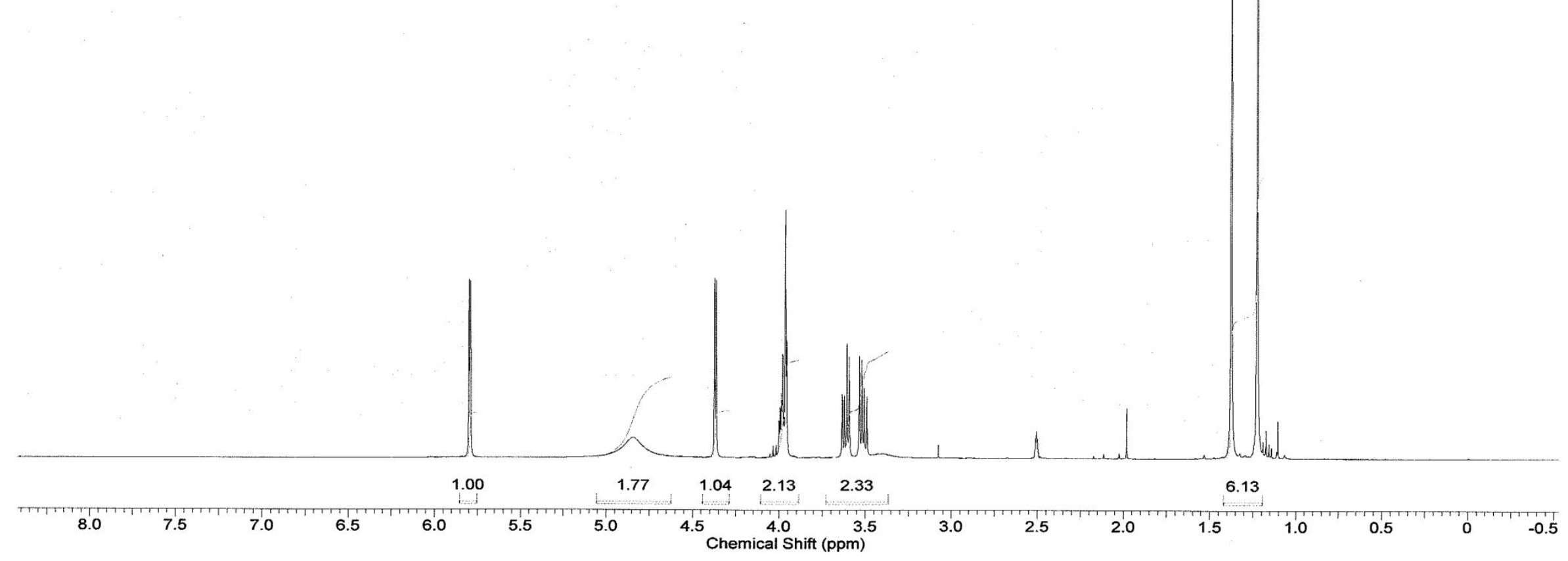


Figure S4. $\quad{ }^{13} \mathrm{C}$ NMR spectrum of monoacetonide 1 (DMSO- $\mathrm{d}_{6}$ )

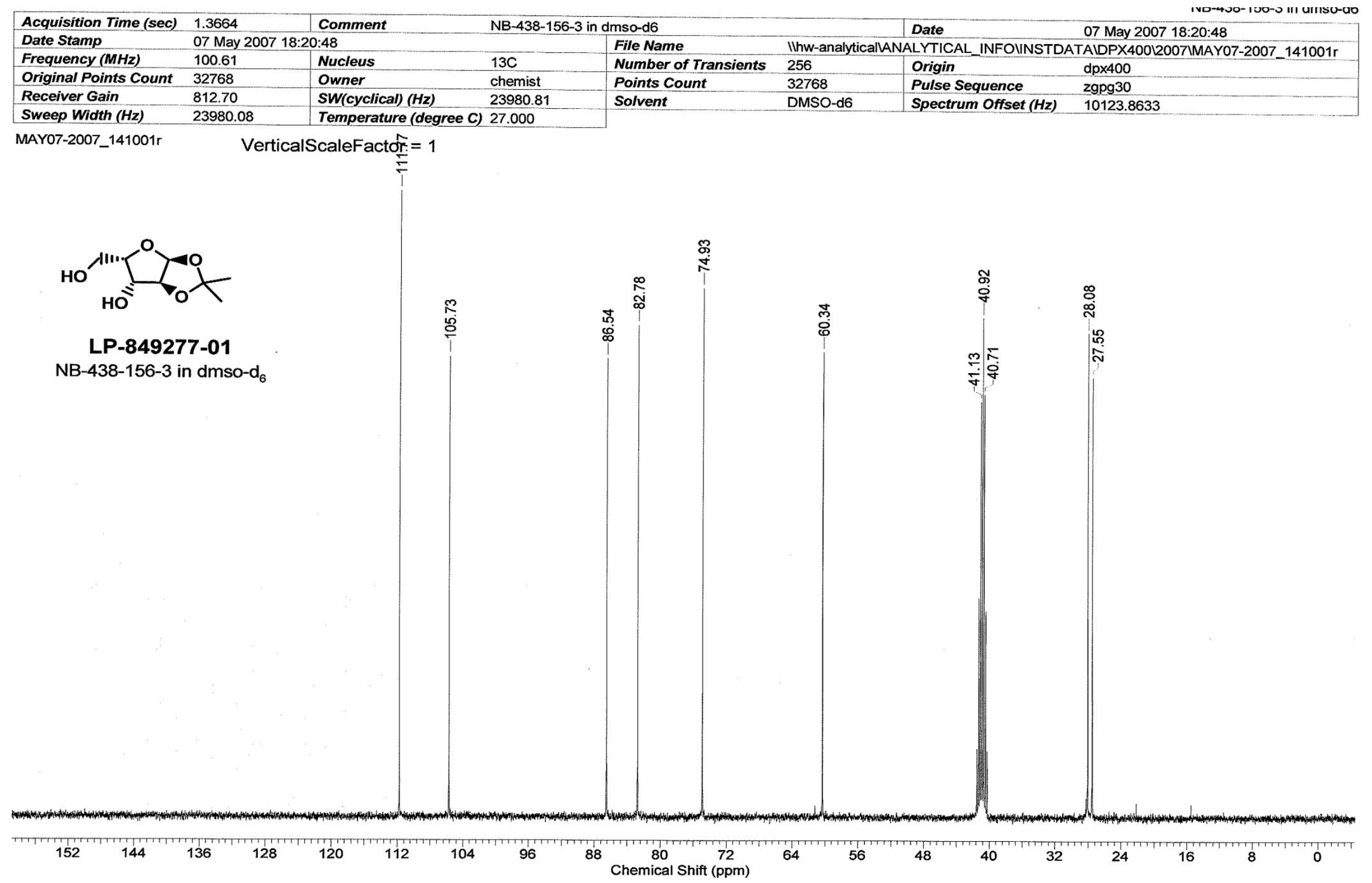


$1.3{ }^{1} \mathrm{H}$ and ${ }^{13} \mathrm{C}$ NMR Spectra of morpholine amide $\mathbf{1 3}$

Figure S5. $\quad{ }^{1} \mathrm{H}$ NMR spectrum of morpholine amide $13\left(\mathrm{CDCl}_{3}\right)$

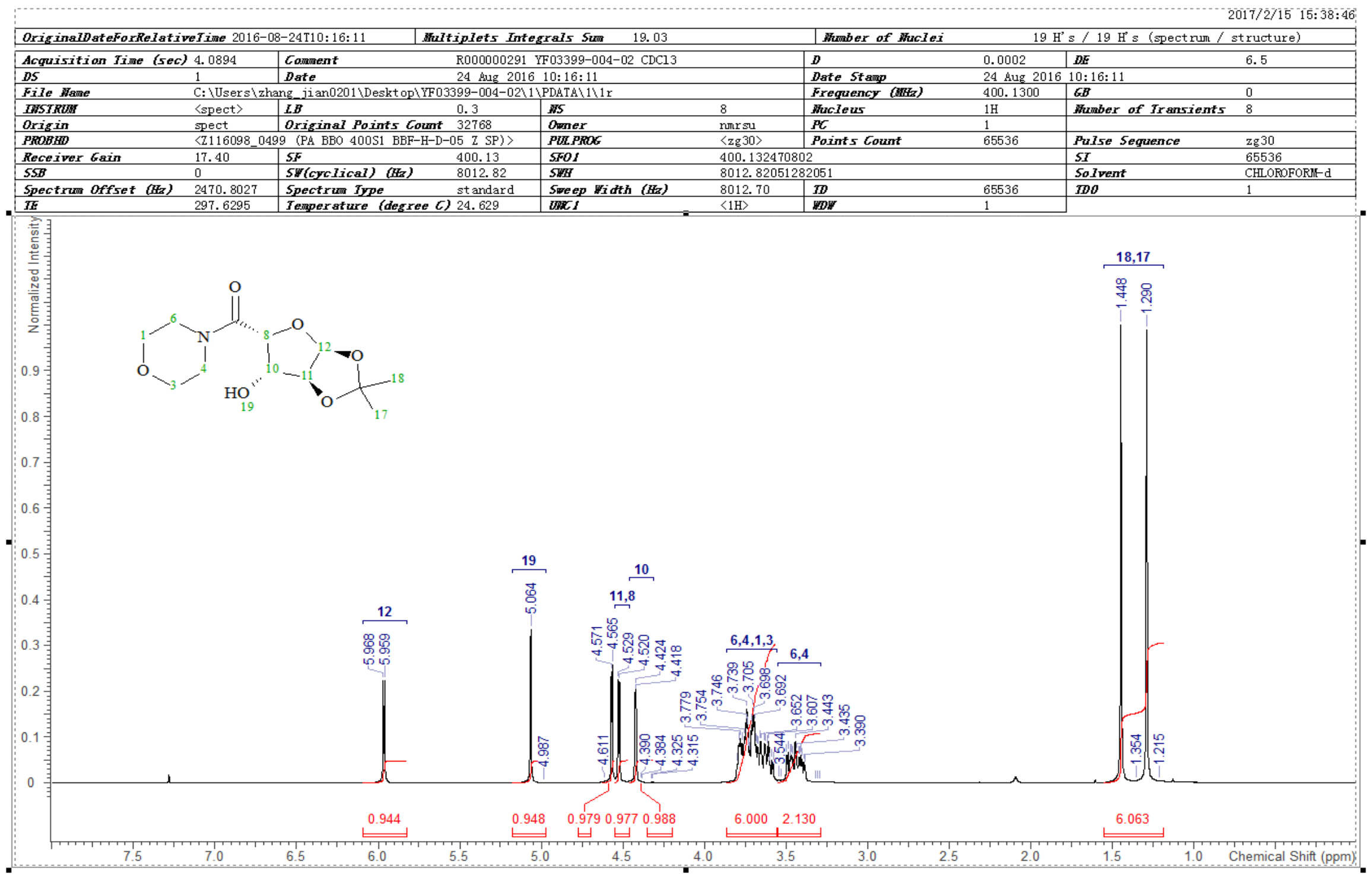


Figure S6. $\quad{ }^{13} \mathrm{C}$ NMR spectrum of morpholine amide $13\left(\mathrm{CDCl}_{3}\right)$

2016/12/12 19:05:54

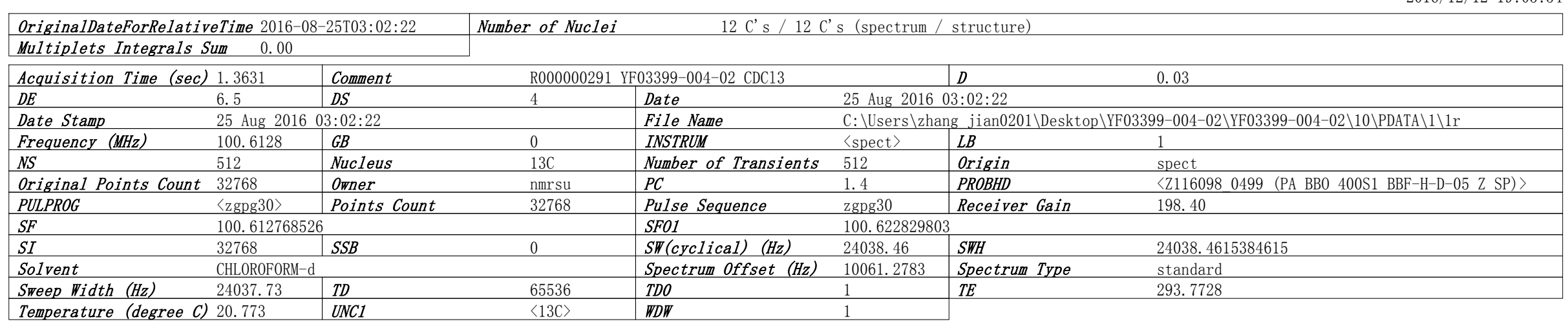

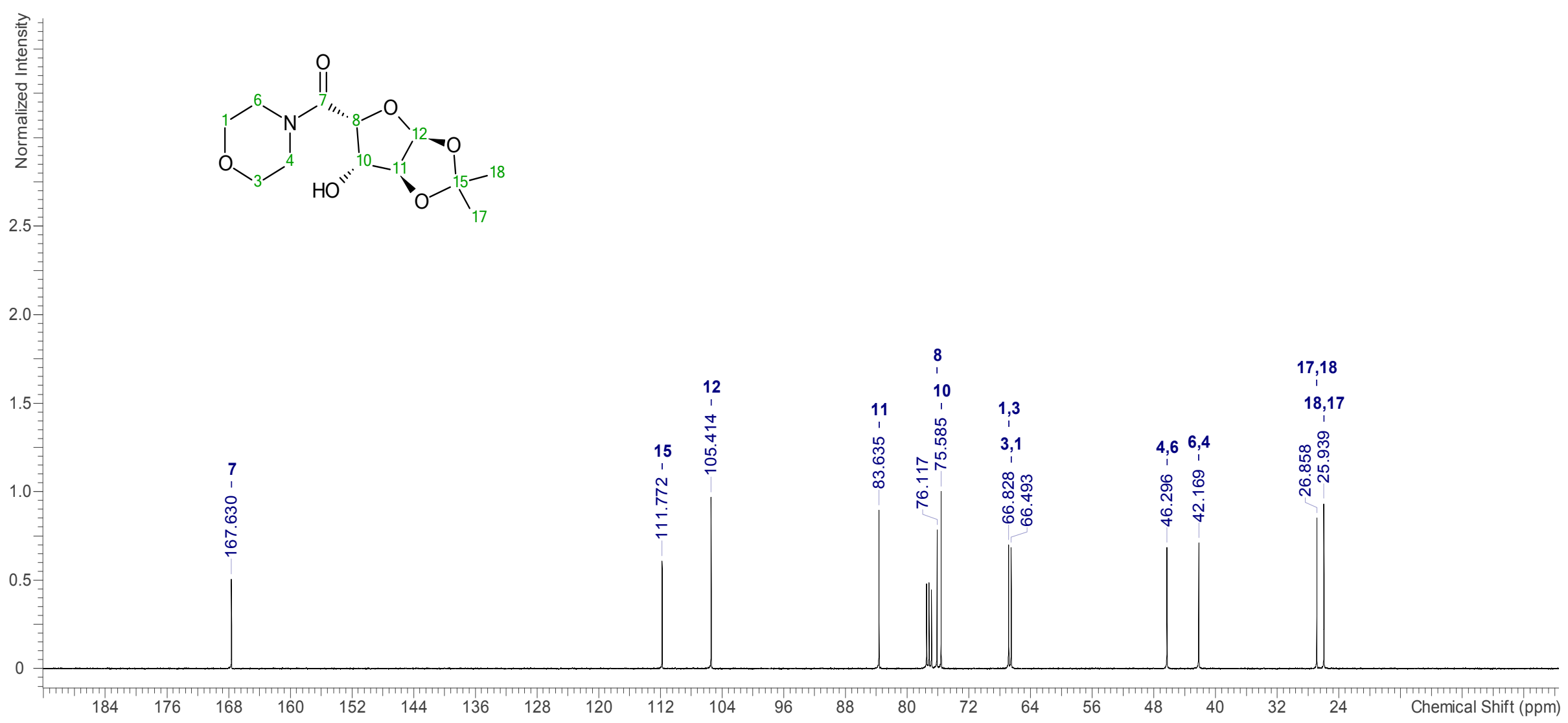


$1.4{ }^{1} \mathrm{H}$ and ${ }^{13} \mathrm{C}$ NMR Spectra of biaryl ketone $\mathbf{1 8}$

Figure S7. $\quad{ }^{1} \mathrm{H}$ NMR spectrum of biaryl ketone $18\left(\mathrm{DMSO}-\mathrm{d}_{6}\right)$

\begin{tabular}{|c|c|c|c|c|c|c|c|}
\hline Acquisition Time (sec) & 4.5351 & Comment & NB-707-S & so-d6 & & Date & 08 Nov 2010 11:29:52 \\
\hline Date Stamp & 08 Nov 2010 & & & & & & \\
\hline File Name & \multicolumn{7}{|c|}{ IVhw-analyticallANALYTICAL_DATAIINSTDATAINMR_DATAINMRIDRX40012010ICHEMISTINOV08-2010140IPDATAI111R } \\
\hline Frequency $(\mathrm{MHz})$ & 400.33 & Nucleus & $1 \mathrm{H}$ & Number of Transients & 64 & Origin & dr $\times 400$ \\
\hline Original Points Count & 32768 & Owner & chemist. & Points Count & 32768 & Pulse Sequence & $\mathrm{zg} 30$ \\
\hline Receiver Gain & 203.20 & SW(cyclical) $(H z)$ & 7225.43 & Solvent & DMSO-d6 & Spectrum Offset $(\mathrm{Hz})$ & 2796.9299 \\
\hline Spectrum Type & STANDARD & Sweep Width $(\mathrm{Hz})$ & 7225.21 & Temperature (degree $C$ & 30.160 & & \\
\hline
\end{tabular}

NOV08-2010_040001r VerticalScaleFactor $=1$

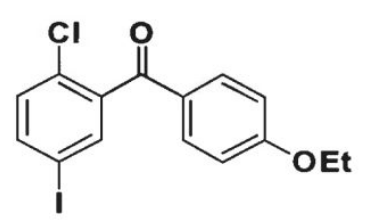

NB-707-98-30 in DMSO- $d_{6}$

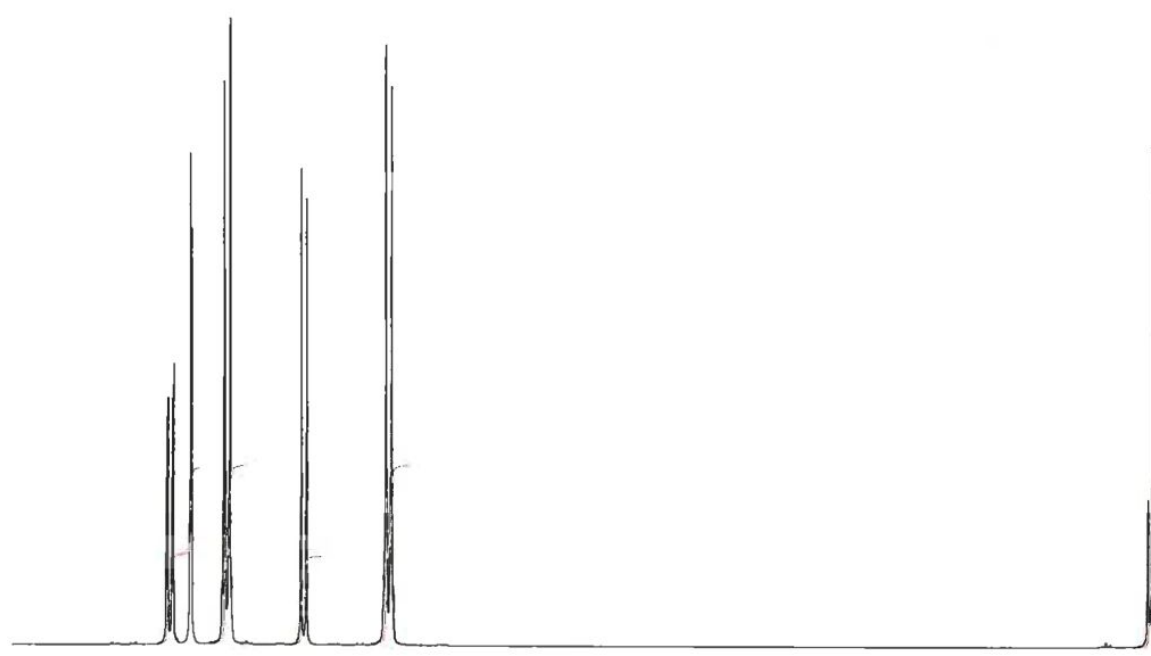

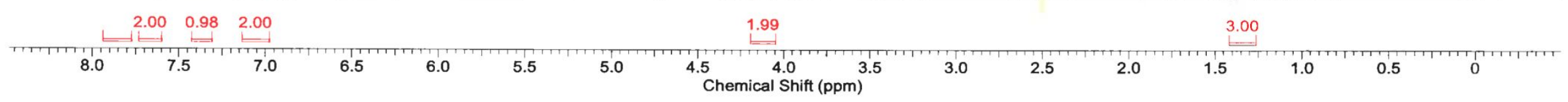


Figure S8. $\quad{ }^{13} \mathrm{C}$ NMR spectrum of biaryl ketone $18\left(\right.$ DMSO- $\left._{6}\right)$

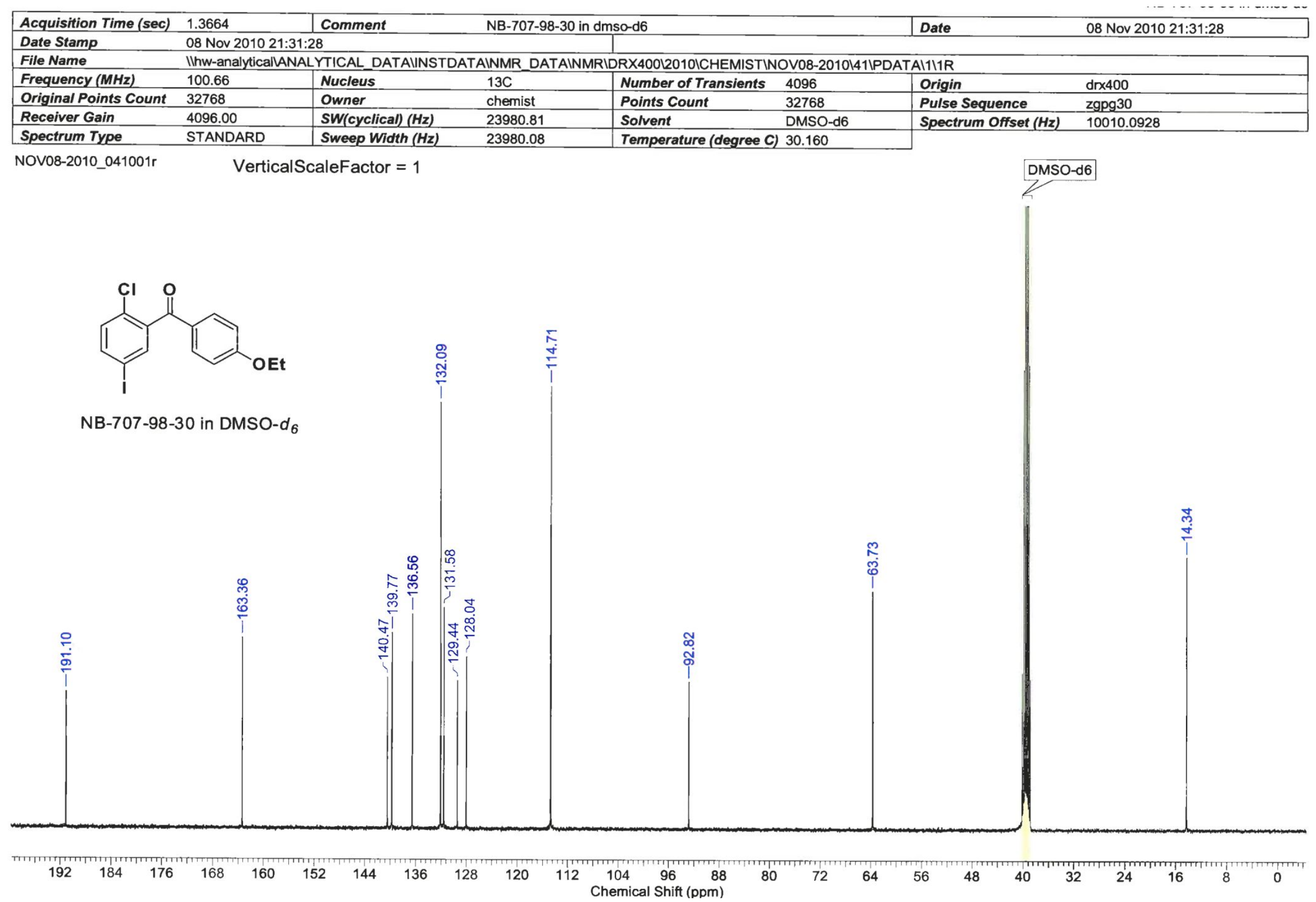


$1.5{ }^{1} \mathrm{H}$ and ${ }^{13} \mathrm{C}$ NMR Spectra of birayl iodide 4

Figure S9. $\quad{ }^{1} \mathrm{H}$ NMR spectrum of biaryl iodide $4\left(\mathrm{CDCl}_{3}\right)$

$2017 / 2 / 1515: 16: 43$

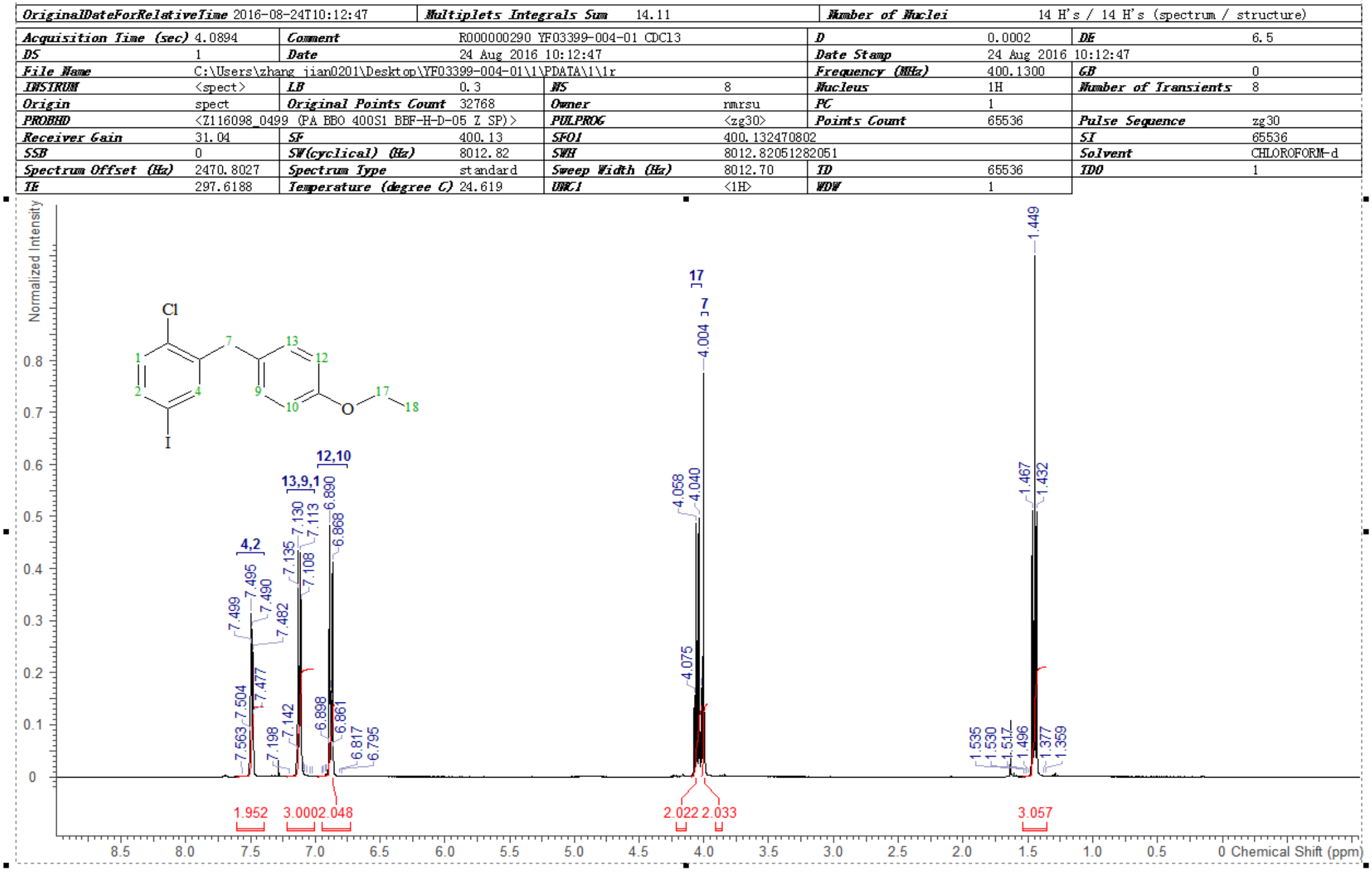


Figure S10. $\quad{ }^{13} \mathrm{C}$ NMR spectrum of biaryl iodide $4\left(\mathrm{CDCl}_{3}\right)$

2016/12/12 19:20:23

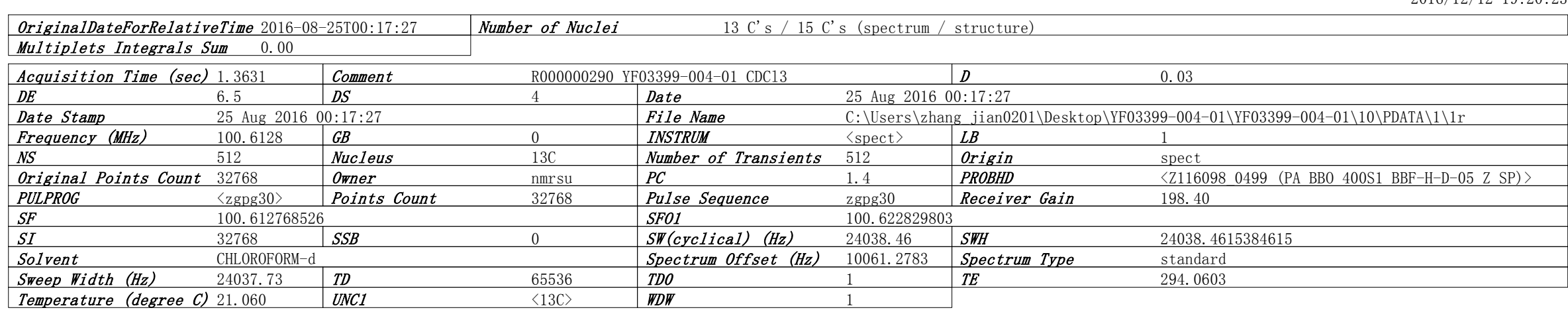

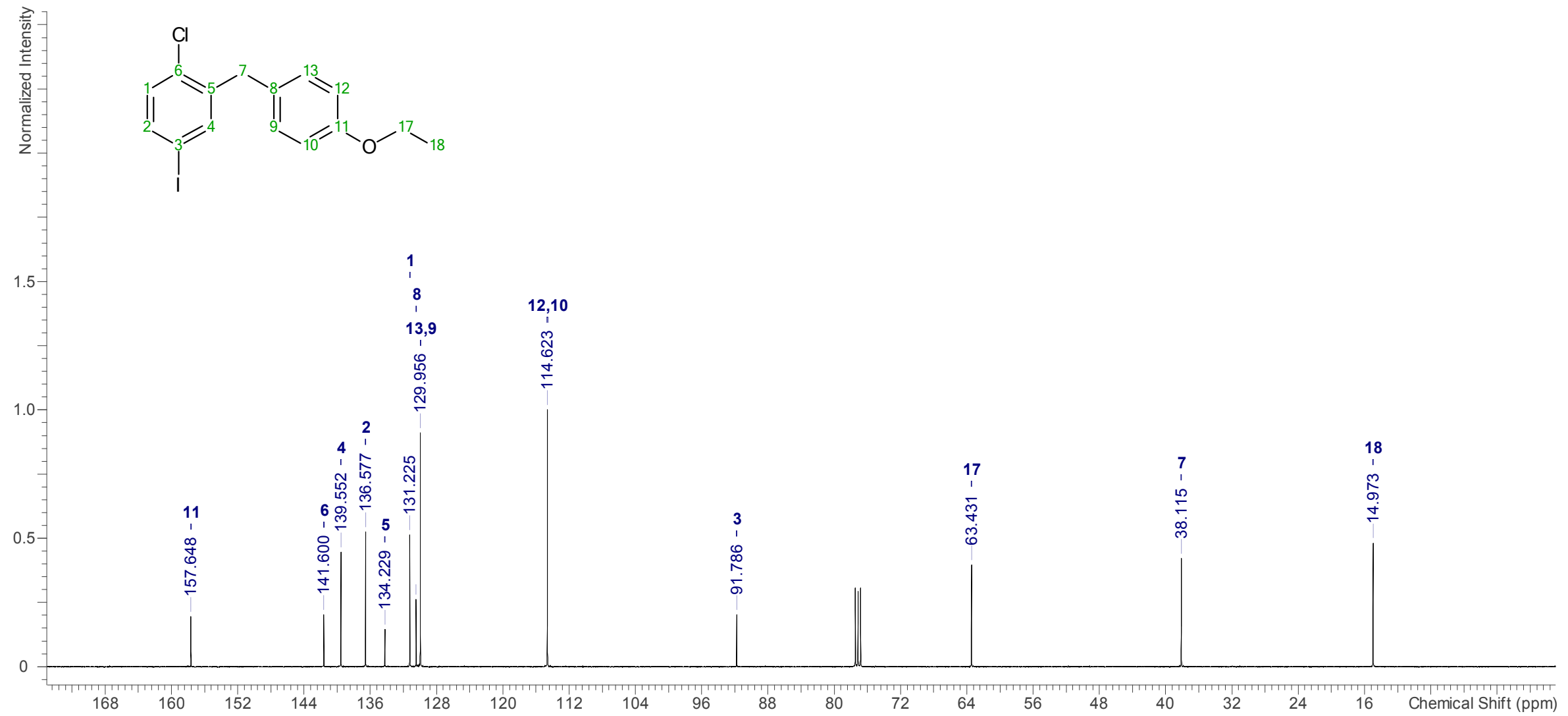


1.6 ${ }^{1} \mathrm{H}$ and ${ }^{13} \mathrm{C}$ NMR Spectra and single crystal X-ray of ketone 6

Figure S11. $\quad{ }^{1} \mathrm{H}$ NMR spectrum of ketone $6\left(\mathrm{CDCl}_{3}\right)$

\begin{tabular}{|c|c|c|c|c|c|c|c|}
\hline \multirow{2}{*}{$\begin{array}{l}\text { Date Stamp } \\
\text { File Name } \\
\end{array}$} & \multicolumn{7}{|c|}{02 Jan 2012 10:32:16 } \\
\hline & \multicolumn{7}{|c|}{ 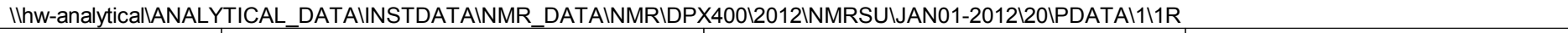 } \\
\hline Frequency (MHz) & 400.13 & Nucleus & $1 \mathrm{H}$ & Number of Transients & 16 & Origin & $\mathrm{dpx} 400$ \\
\hline Original Points Count & 32768 & Owner & nmrsu & Points Count & 32768 & Pulse Sequence & $\mathrm{zg} 30$ \\
\hline Receiver Gain & 143.70 & SW(cyclical) (Hz) & 8278.15 & Solvent & CHLOROFORM-d & Spectrum Offset (Hz) & 2465.9602 \\
\hline Spectrum Type & STANDARD & Sweep Width $(\mathrm{Hz})$ & 8277.89 & Temperature (degree C & 27.000 & & \\
\hline
\end{tabular}

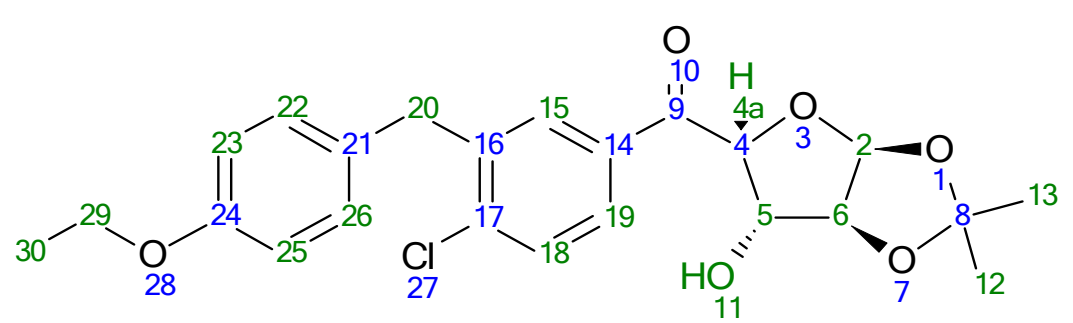

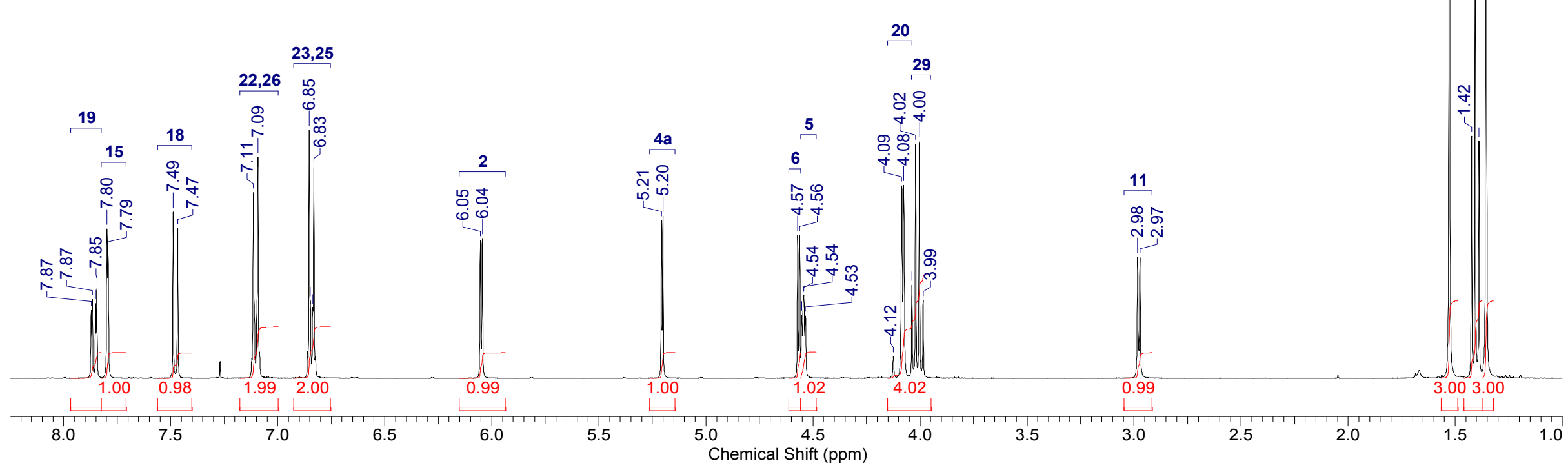


Figure S12. $\quad{ }^{13} \mathrm{C}$ NMR spectrum of ketone $6\left(\mathrm{CDCl}_{3}\right)$

\begin{tabular}{|c|c|c|c|c|c|c|}
\hline Acquisition Time (sec) & 1.3664 & Comment & \multicolumn{2}{|c|}{ NB-597-31 structure assignment on $29.7 \mathrm{mg}$ in $750 \mathrm{ul} \mathrm{cdcl} 3$} & Date & 03 Jan 2012 05:29:20 \\
\hline Date Stamp & \multicolumn{4}{|c|}{ 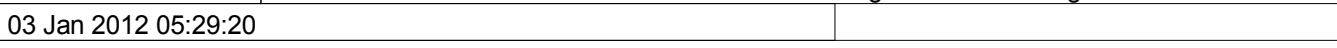 } & & \\
\hline File Name & \multicolumn{4}{|c|}{ IIhw-analyticallAnalytical_DatalINSTDATAINMR_DATAINMRIDPX400|2012INMRSUIJAN01-2012|25IPDATAI1|1R } & Frequency $(\mathrm{MHz})$ & 100.61 \\
\hline Nucleus & \begin{tabular}{l|l}
$13 \mathrm{C}$ & \\
\end{tabular} & Number of Transients & 8192 & Origin $\quad \mathrm{dpx} 400$ & Original Points Count & 32768 \\
\hline Owner & nmrsu & Points Count & 32768 & Pulse Sequence & Receiver Gain & 4096.00 \\
\hline SW(cyclical) $(\mathrm{Hz})$ & 23980.81 & Solvent & CHLOROFORM-d & Spectrum Offset $(\mathrm{Hz})$ & Spectrum Type & STANDARD \\
\hline Sweep Width $(\mathrm{Hz})$ & 23980.08 & Temperature (degree C) & 27.000 & & & \\
\hline
\end{tabular}

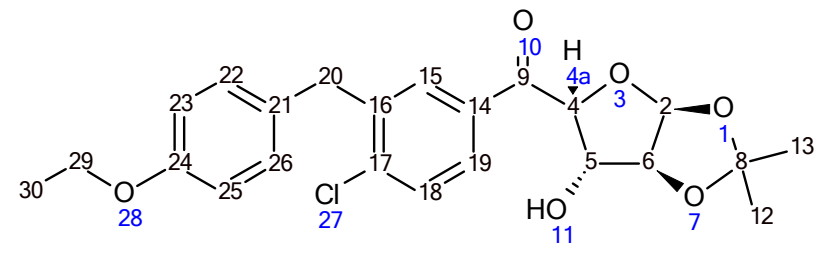

18

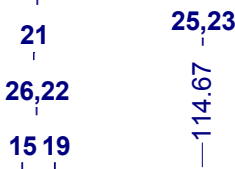

9

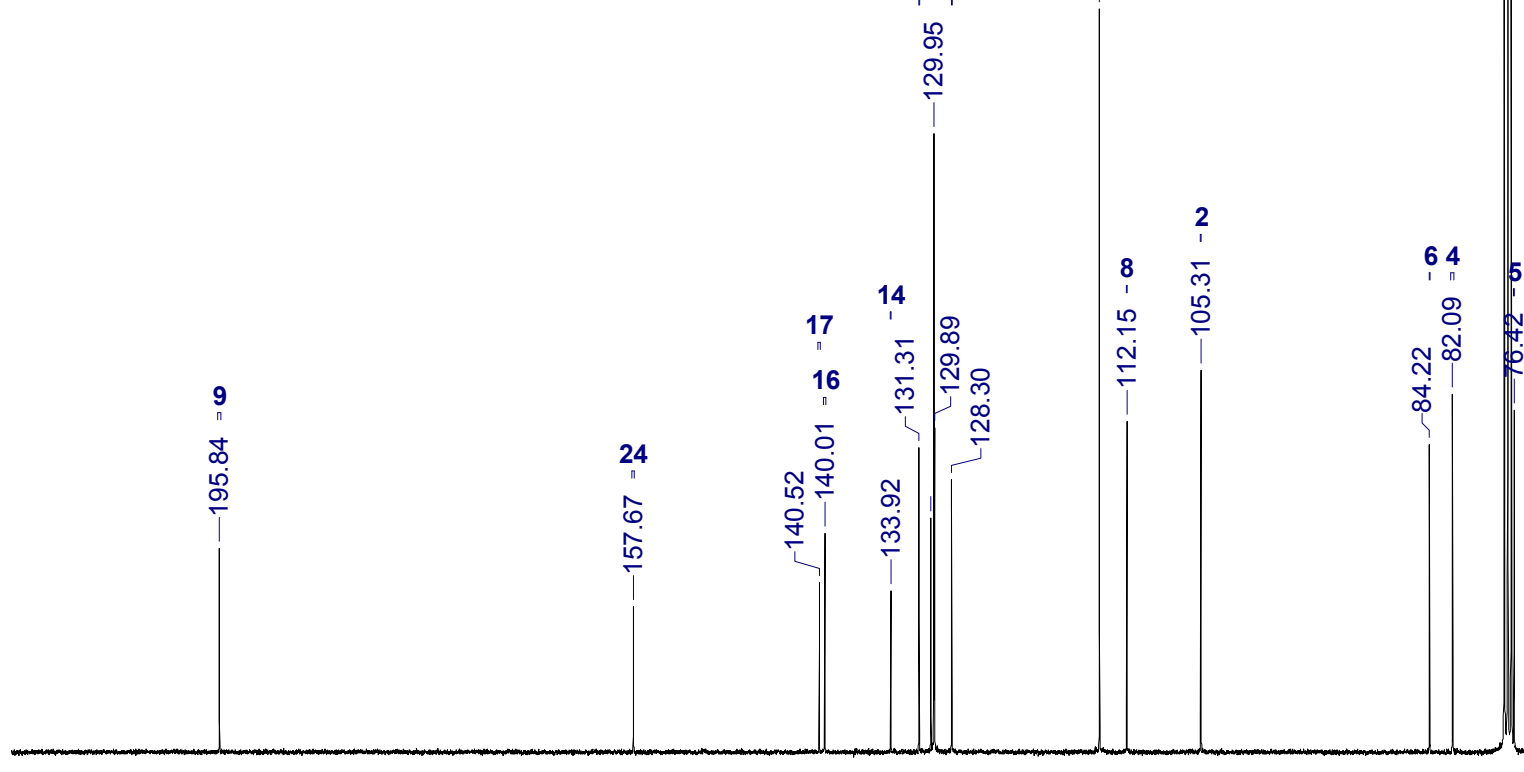

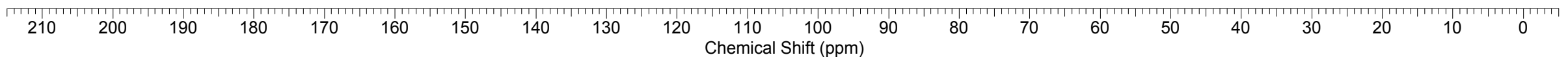


Figure S13. Single crystal X-ray crystallography of ketone 6

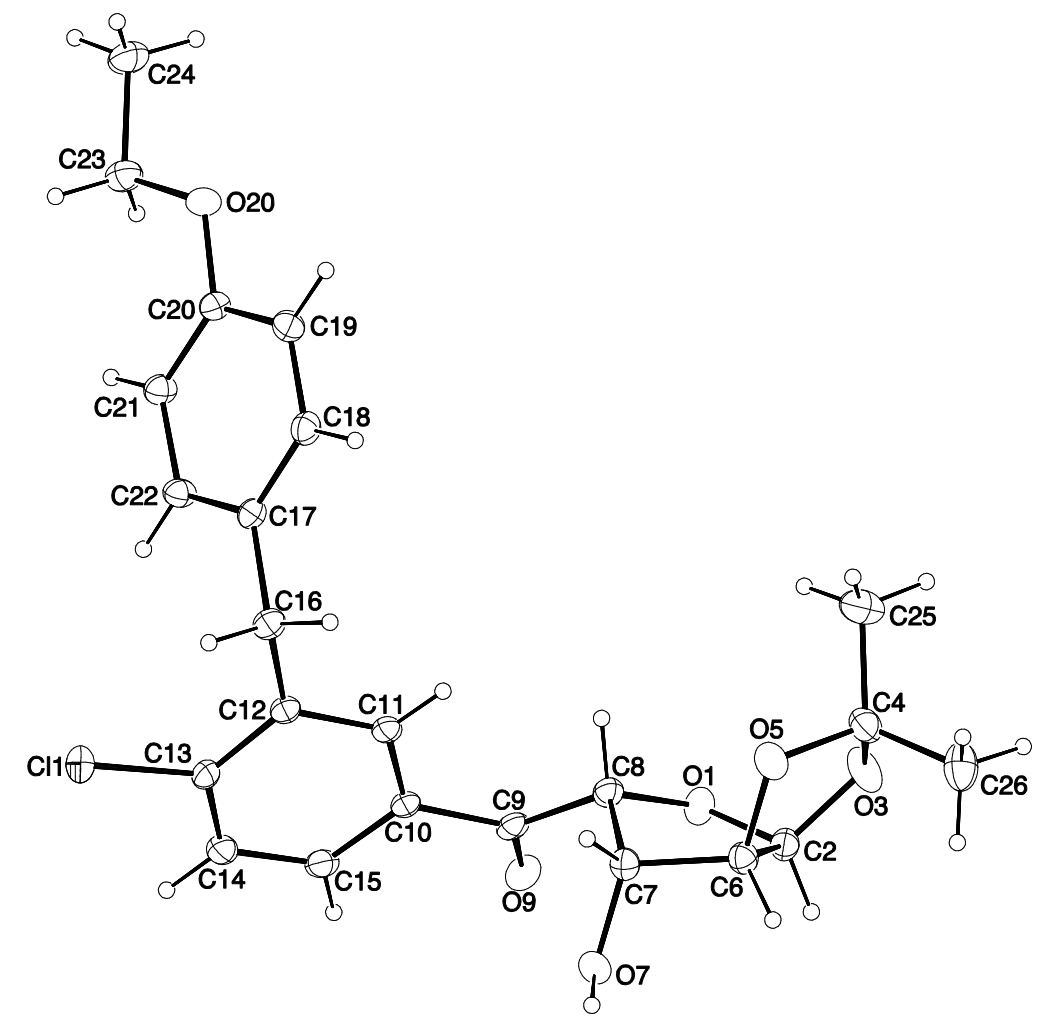

Note: ORTEP drawing of molecule of the asymmetric unit with $30 \%$ probability thermal ellipsoids.

Table S1. Crystal data of ketone 6

\begin{tabular}{|c|c|c|}
\hline Empirical formula & \multicolumn{2}{|l|}{$\mathrm{C}_{23} \mathrm{H}_{25} \mathrm{O}_{6} \mathrm{Cl}$} \\
\hline Formula weight & \multicolumn{2}{|l|}{432.88} \\
\hline Temperature & \multicolumn{2}{|l|}{$143(1) \mathrm{K}$} \\
\hline Wavelength & \multicolumn{2}{|l|}{$0.71073 \AA$} \\
\hline Crystal size & \multicolumn{2}{|c|}{$0.36 \times 0.18 \times 0.12 \mathrm{~mm}$} \\
\hline Crystal system & \multicolumn{2}{|c|}{ Triclinic } \\
\hline Space group & \multicolumn{2}{|l|}{$\mathrm{P} 1$} \\
\hline Unit cell dimensions & $\begin{array}{l}\mathrm{a}=7.4248(5) \AA \\
\mathrm{b}=10.7273(6) \AA \\
\mathrm{c}=15.1701(9) \AA\end{array}$ & $\begin{array}{l}\alpha=93.44^{\circ} \\
\beta=100.17^{\circ} \\
\gamma=107.49^{\circ}\end{array}$ \\
\hline Volume & \multicolumn{2}{|l|}{$1126.07(12) \AA^{3}$} \\
\hline $\mathbf{Z}$ & \multicolumn{2}{|l|}{2} \\
\hline Density (calculated) & \multicolumn{2}{|l|}{$1.277 \mathrm{Mg} / \mathrm{m}^{3}$} \\
\hline Absorption coefficient & \multicolumn{2}{|l|}{$0.205 \mathrm{~mm}^{-1}$} \\
\hline $\mathbf{F ( 0 0 0 )}$ & \multicolumn{2}{|l|}{456} \\
\hline
\end{tabular}


$1.7{ }^{1} \mathrm{H}$ and ${ }^{13} \mathrm{C}$ NMR spectra of diol $7 \boldsymbol{S}$

Figure S14. $\quad{ }^{1} \mathrm{H}$ NMR spectrum of diol $7 S\left(\mathrm{CDCl}_{3}\right)$

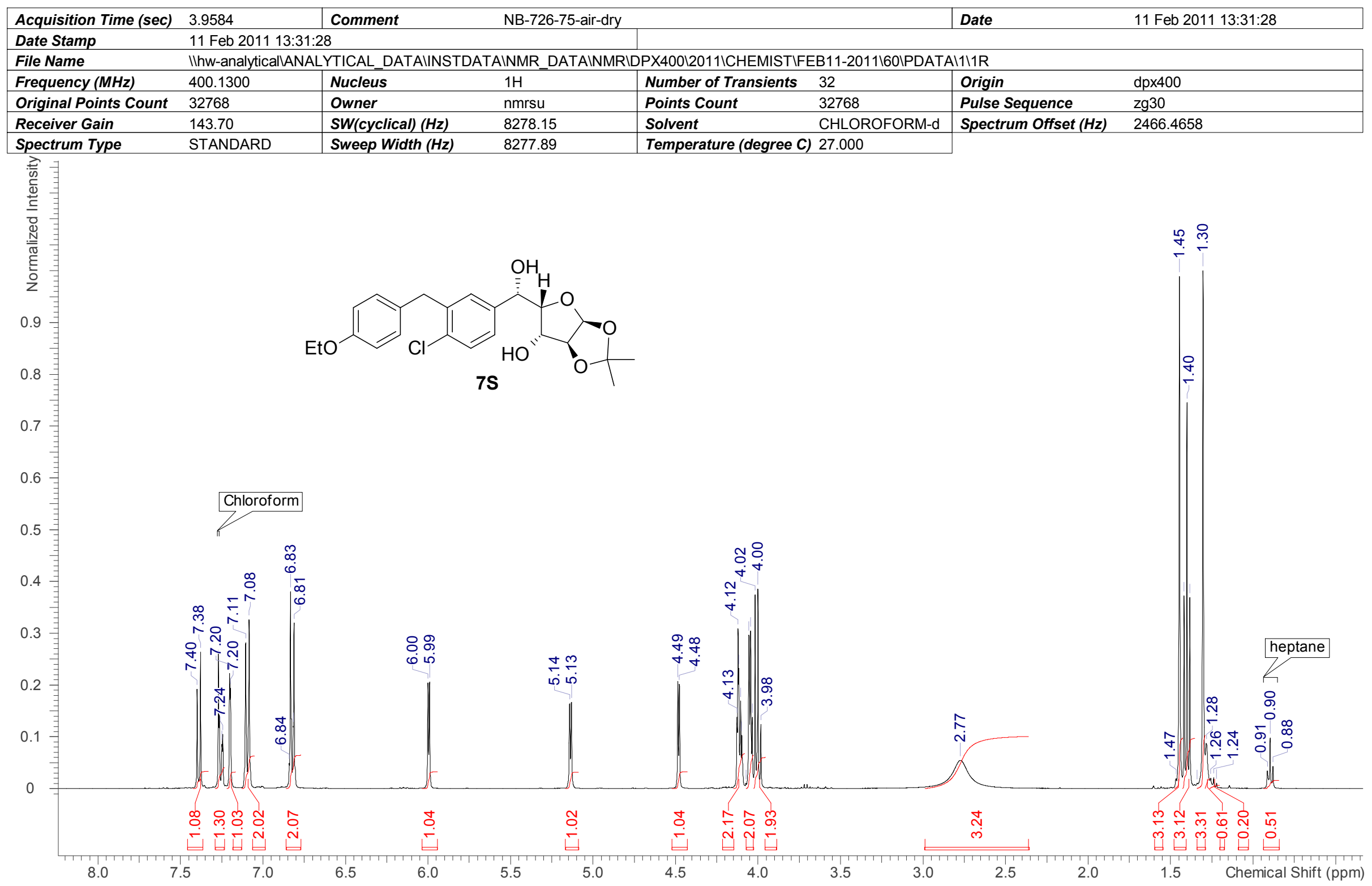


Figure $\mathrm{S} 15 . \quad{ }^{13} \mathrm{C}$ NMR spectrum of diol $7 S\left(\mathrm{CDCl}_{3}\right)$

\section{NB-726-75-air-dry LX4211 diol}

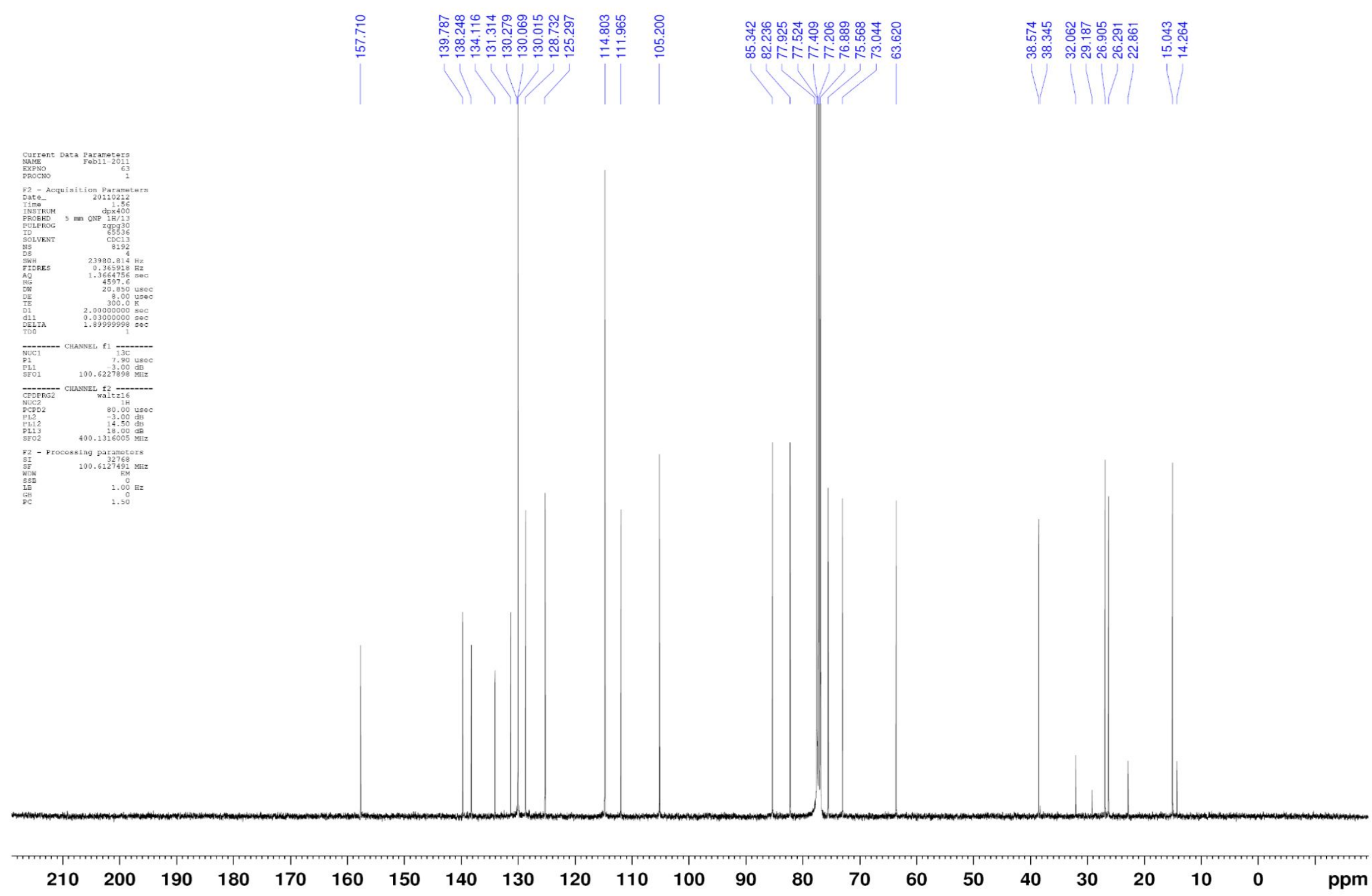


$1.8{ }^{1} \mathrm{H}$ and ${ }^{13} \mathrm{C}$ NMR spectra of tetraol 8

Figure S16. $\quad{ }^{1} \mathrm{H}$ NMR spectrum of tetraol $8\left(\mathrm{DMSO}^{-\mathrm{d}_{6}}\right)$

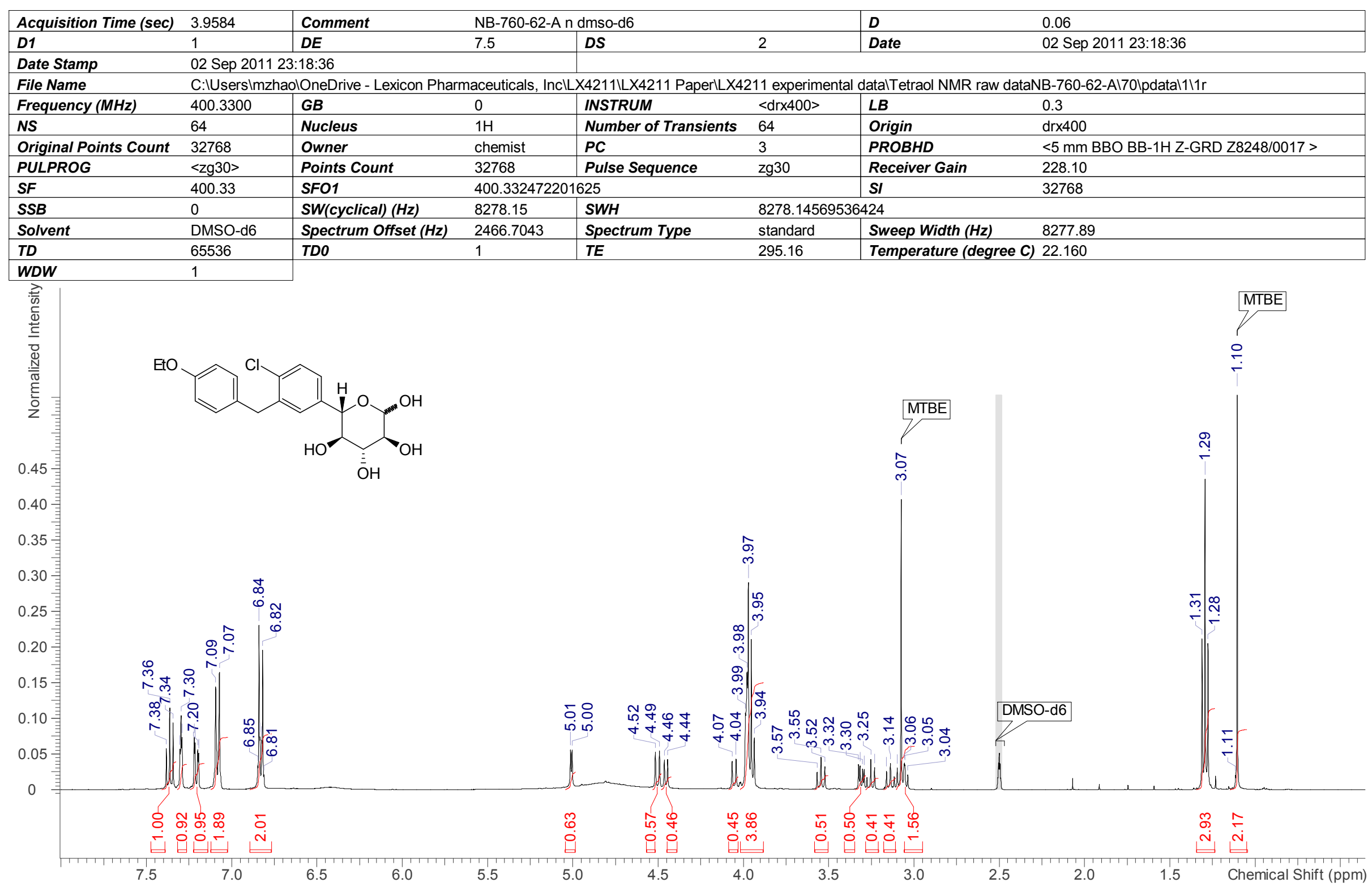


Figure S17. $\quad{ }^{13} \mathrm{C}$ NMR spectrum of tetraol $8\left(\mathrm{DMSO}^{-\mathrm{d}_{6}}\right)$

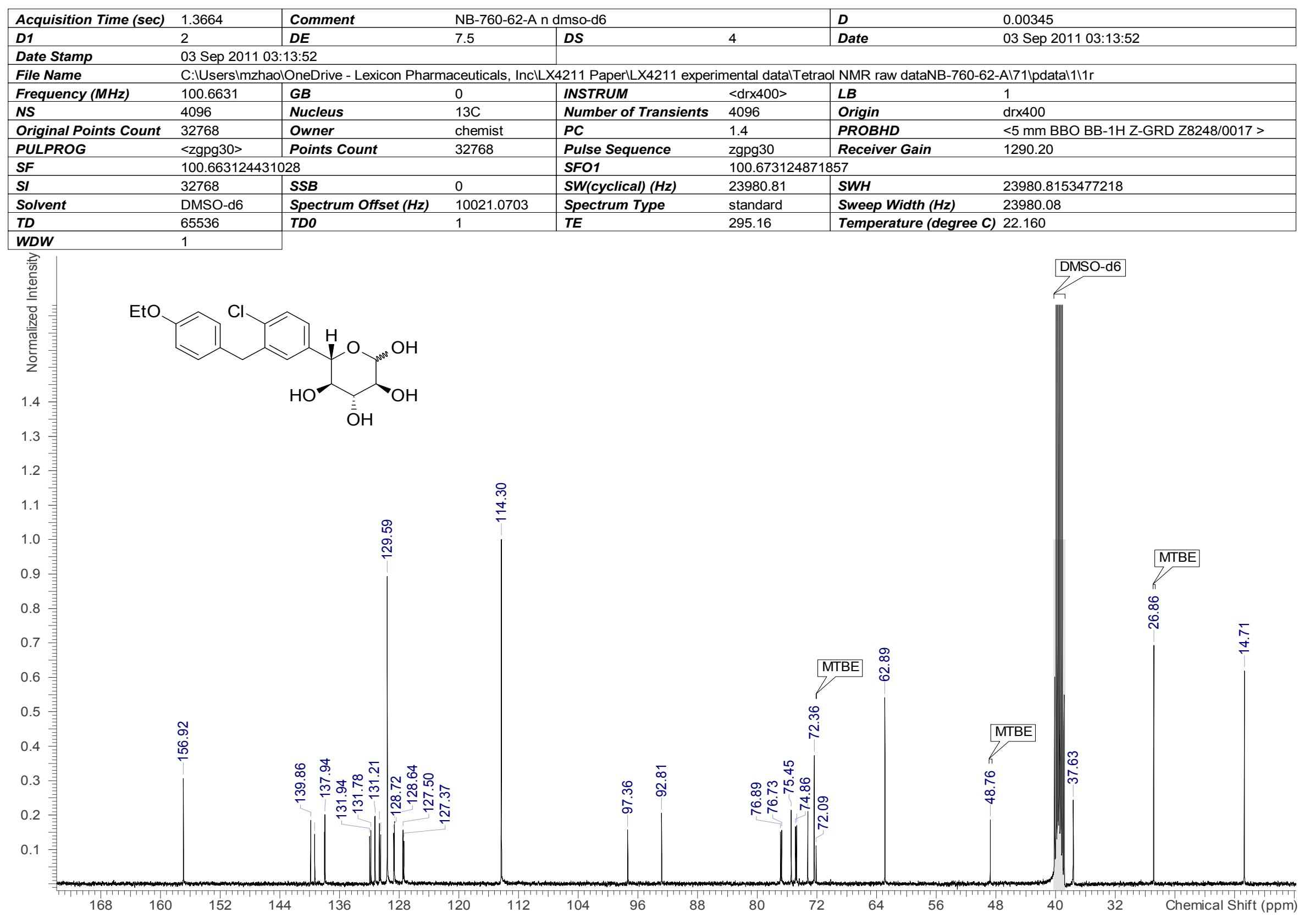


$1.9{ }^{1} \mathrm{H}$ and ${ }^{13} \mathrm{C}$ NMR spectra of tetraacetate $9 \boldsymbol{R}$

Figure S18. $\quad{ }^{1} \mathrm{H}$ NMR spectrum of tetraacetate $9 \boldsymbol{R}\left(\mathrm{DMSO}-\mathrm{d}_{6}\right)$

\section{NB-726-104-C-oven-dry DMSO}

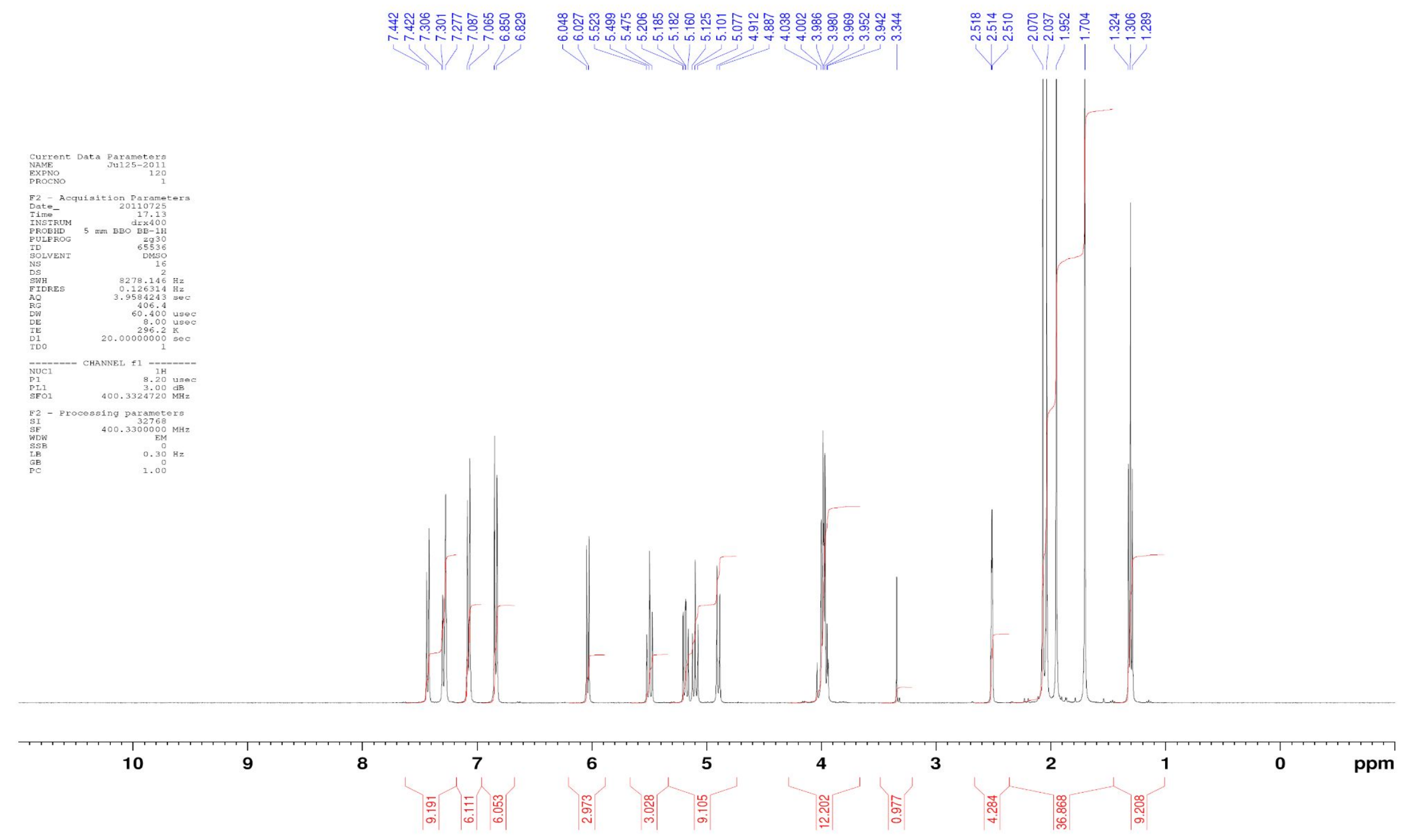


Figure S19. $\quad{ }^{13} \mathrm{C}$ NMR spectrum of tetraacetate $\mathbf{9 R}\left(\mathrm{DMSO}-\mathrm{d}_{6}\right)$

NB-726-104-C-oven-dry DMSO

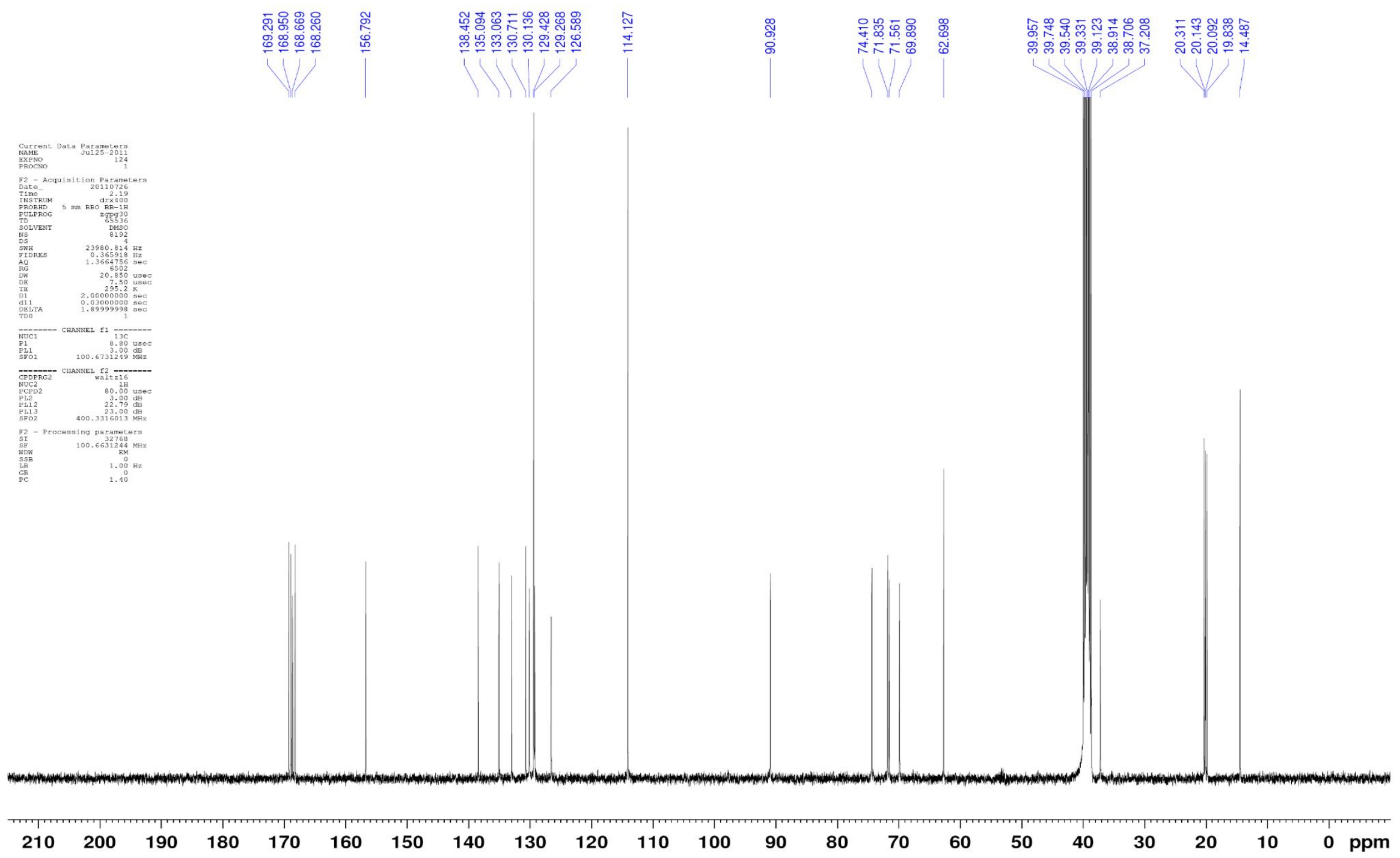


$1.10^{1} \mathrm{H}$ and ${ }^{13} \mathrm{C}$ NMR spectra for isothiourea 23

Figure S20. $\quad{ }^{1} \mathrm{H}$ NMR spectrum of isothiourea $23\left(\right.$ DMSO- $\left._{6}\right)$

\section{NB-726-102-water-washed solid}

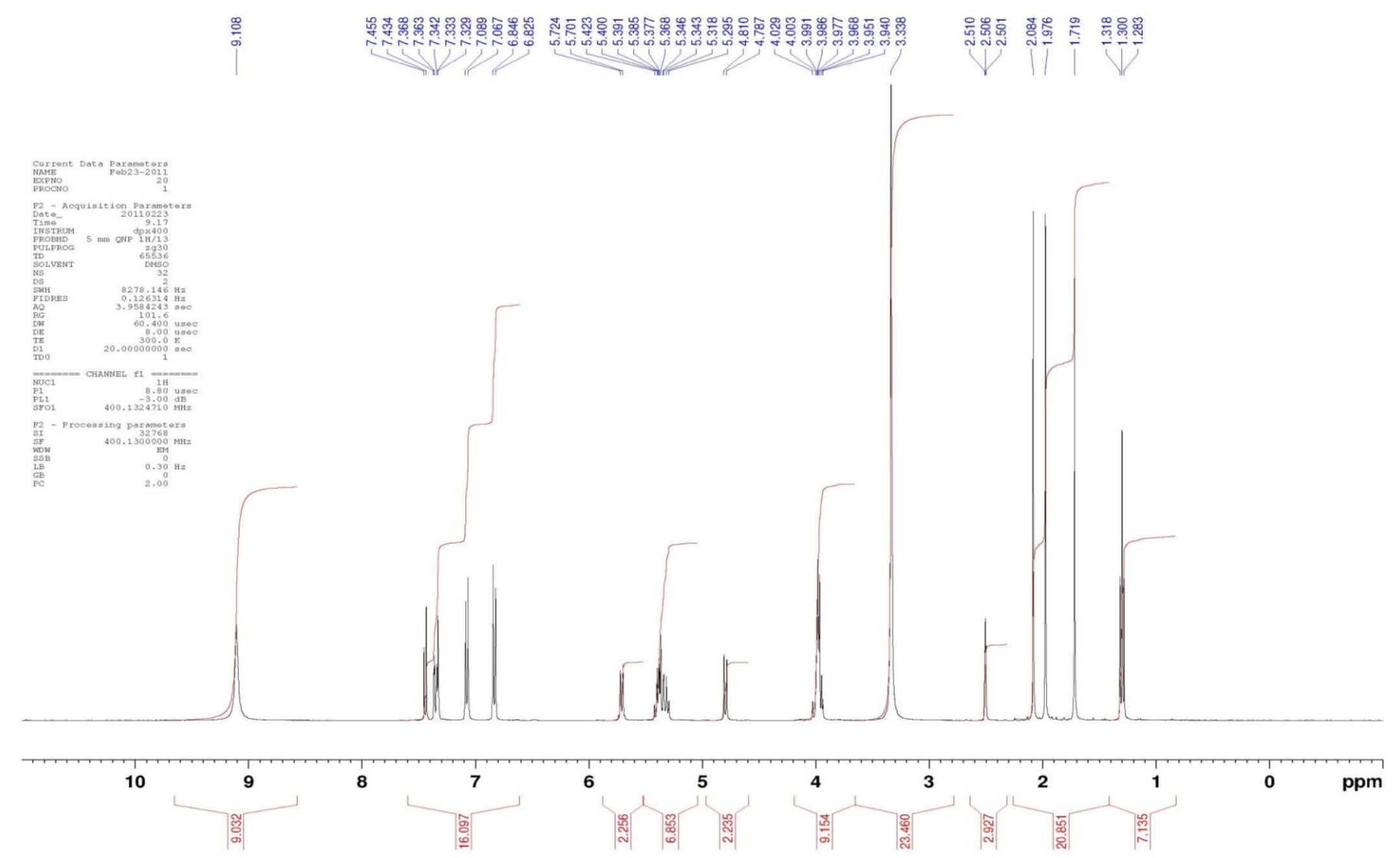


Figure S21. ${ }^{13} \mathrm{C}$ NMR spectrum of isothiourea $23\left(\mathrm{DMSO}-\mathrm{d}_{6}\right)$

\section{NB-726-102-water-washed solid}

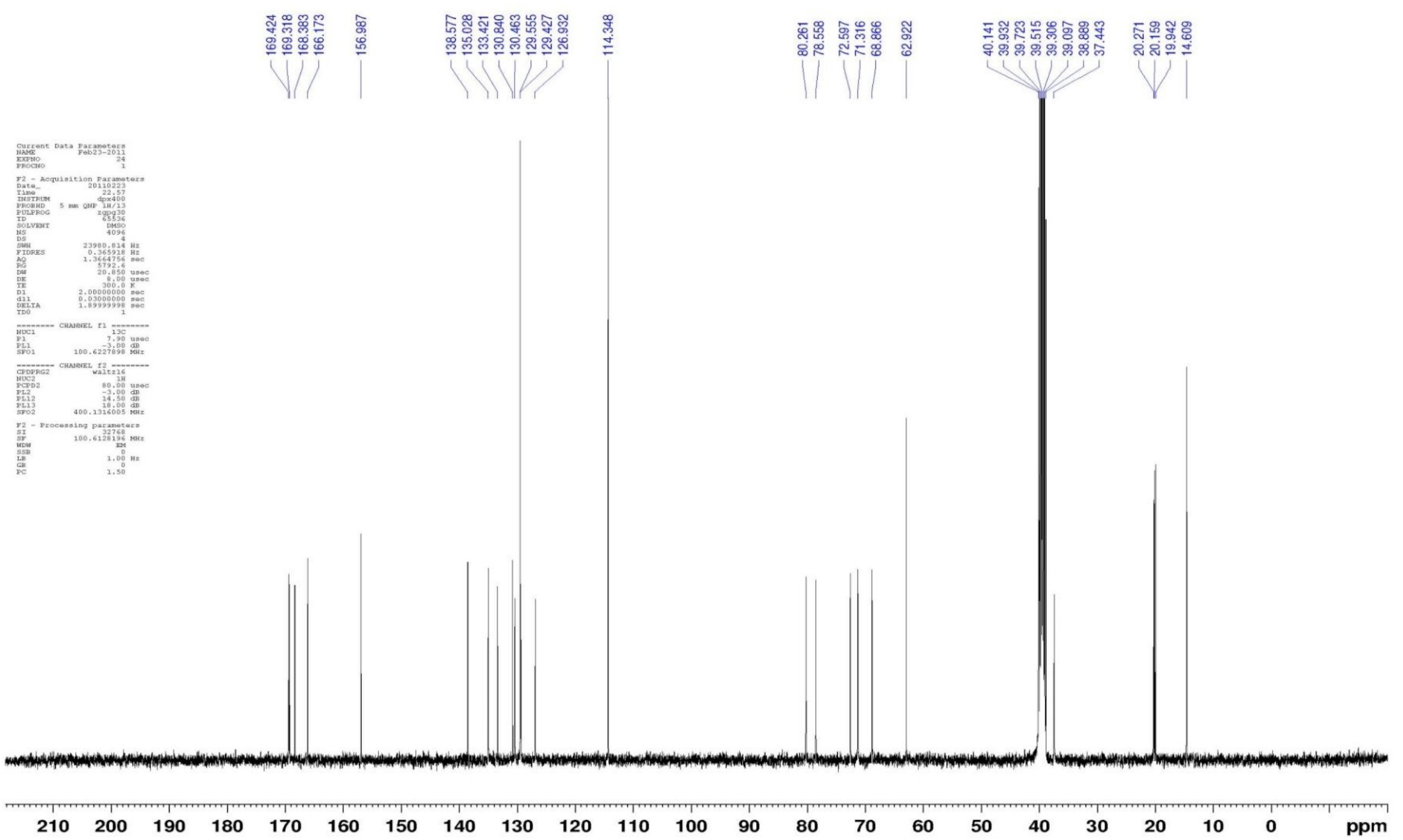




\section{$1.11^{1} \mathrm{H}$ and ${ }^{13} \mathrm{C}$ NMR spectra of triacetate $\mathbf{1 0 R}$}

Figure S22. $\quad{ }^{1} \mathrm{H}$ NMR spectrum of triacetate $\mathbf{1 0 R}\left(\mathrm{DMSO}-\mathrm{d}_{6}\right)$

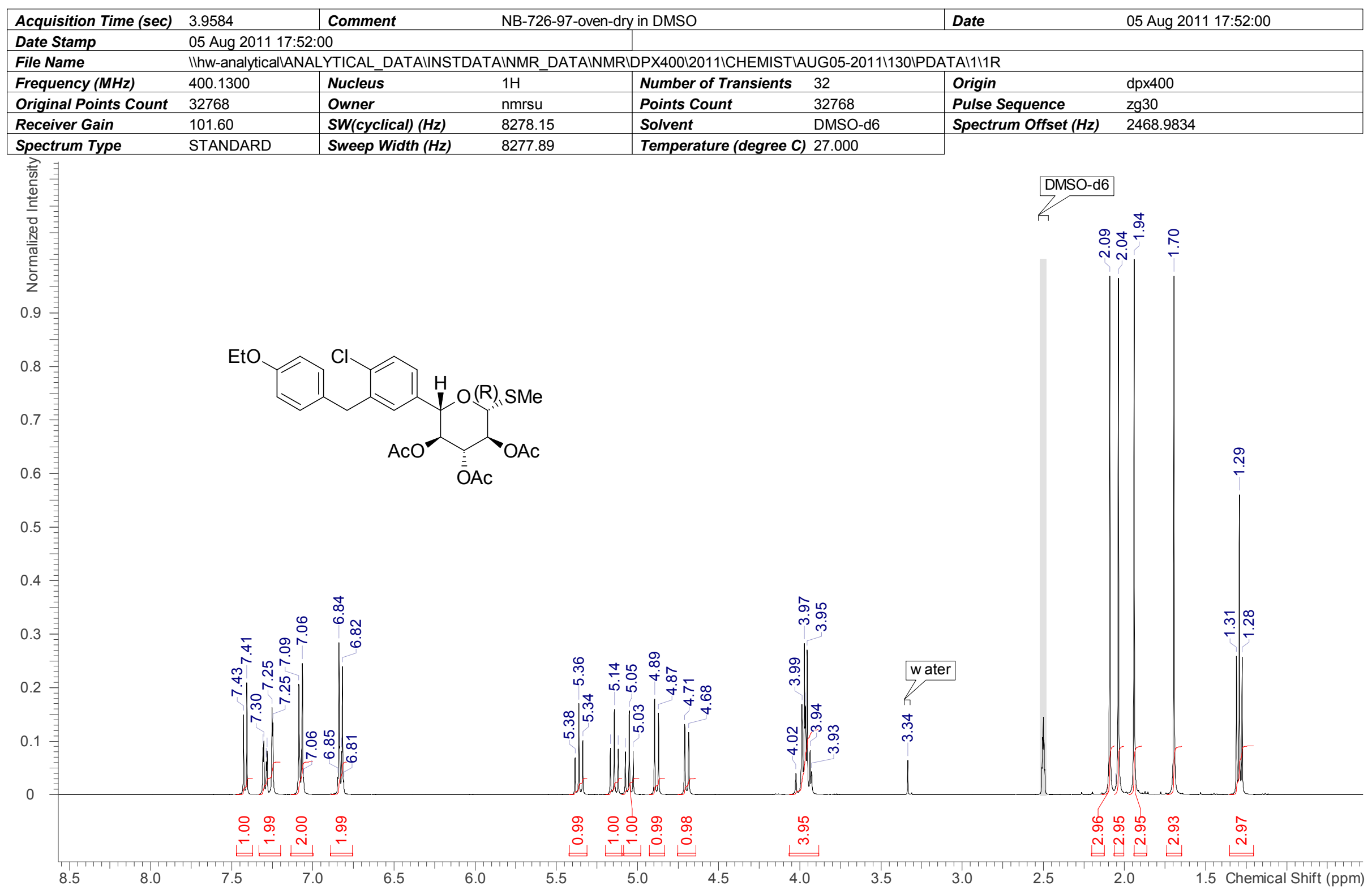


Figure S23. ${ }^{13} \mathrm{C}$ NMR spectrum of triacetate $\mathbf{1 0} \boldsymbol{R}\left(\mathrm{DMSO}-\mathrm{d}_{6}\right)$

\section{NB-726-97-oven-dry in DMSO}

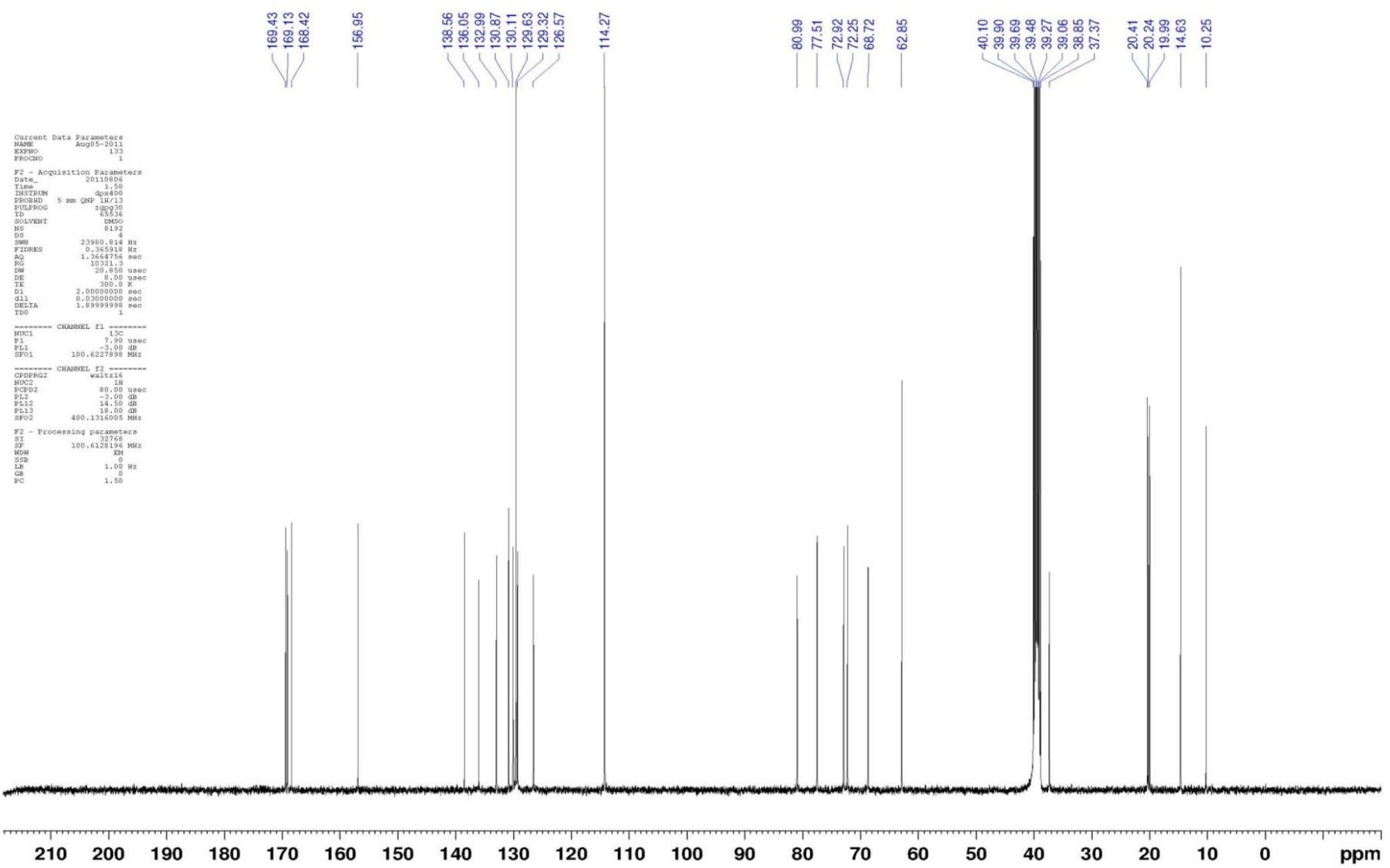


$1.12{ }^{1} \mathrm{H}$ and ${ }^{13} \mathrm{C}$ NMR spectra and single crystal X-ray of sotagliflozin

Figure S24. $\quad{ }^{1} \mathrm{H}$ NMR spectrum of sotagliflozin $\left(\mathrm{DMSO}-\mathrm{d}_{6}\right)$

\section{NB-726-115-oven-dry LX4211 from MeOH-water}

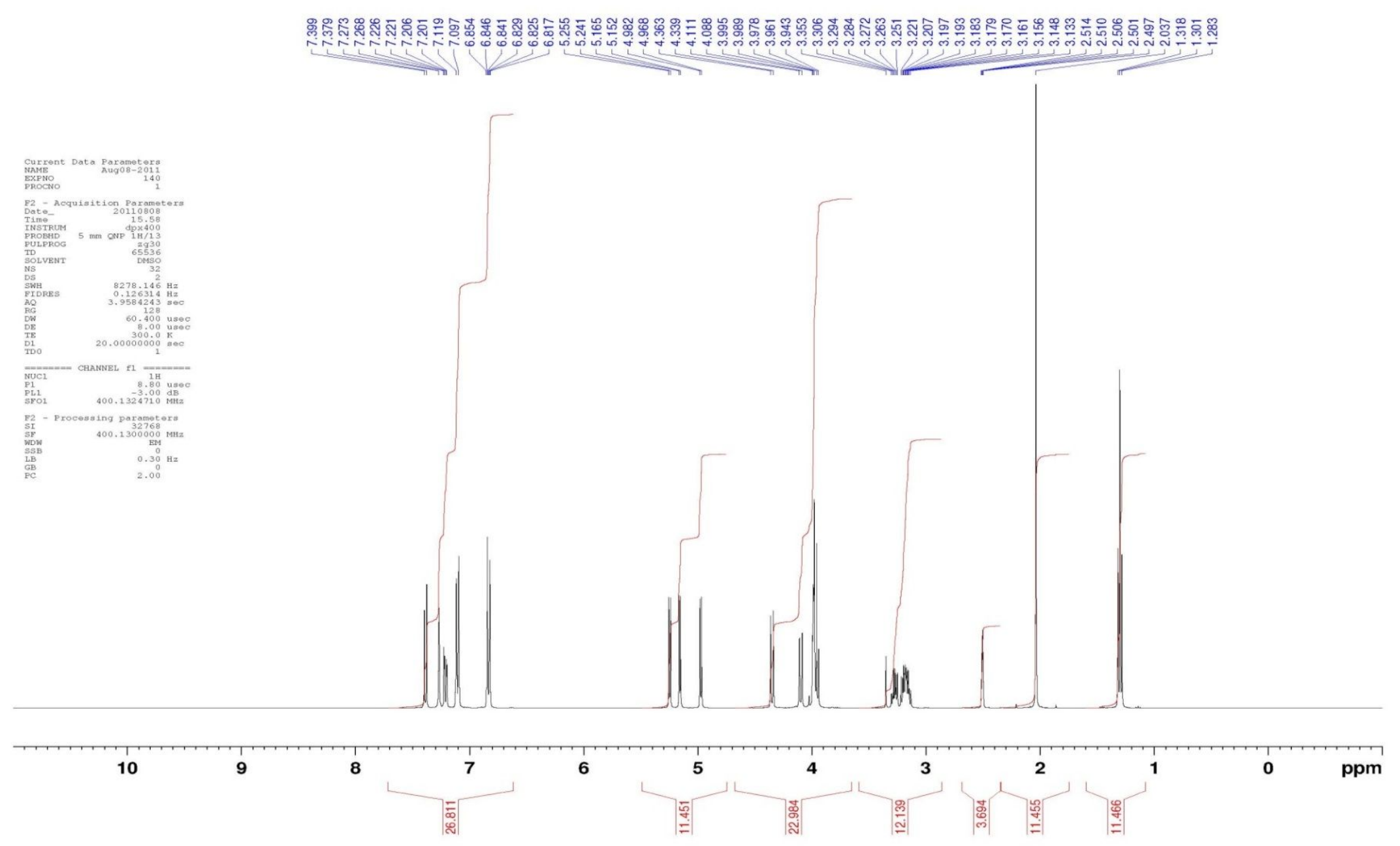


Figure S25. $\quad{ }^{13} \mathrm{C}$ NMR spectrum of sotagliflozin (DMSO- $\mathrm{d}_{6}$ )

\section{NB-726-115-oven-dry LX4211 from MeOH-water}

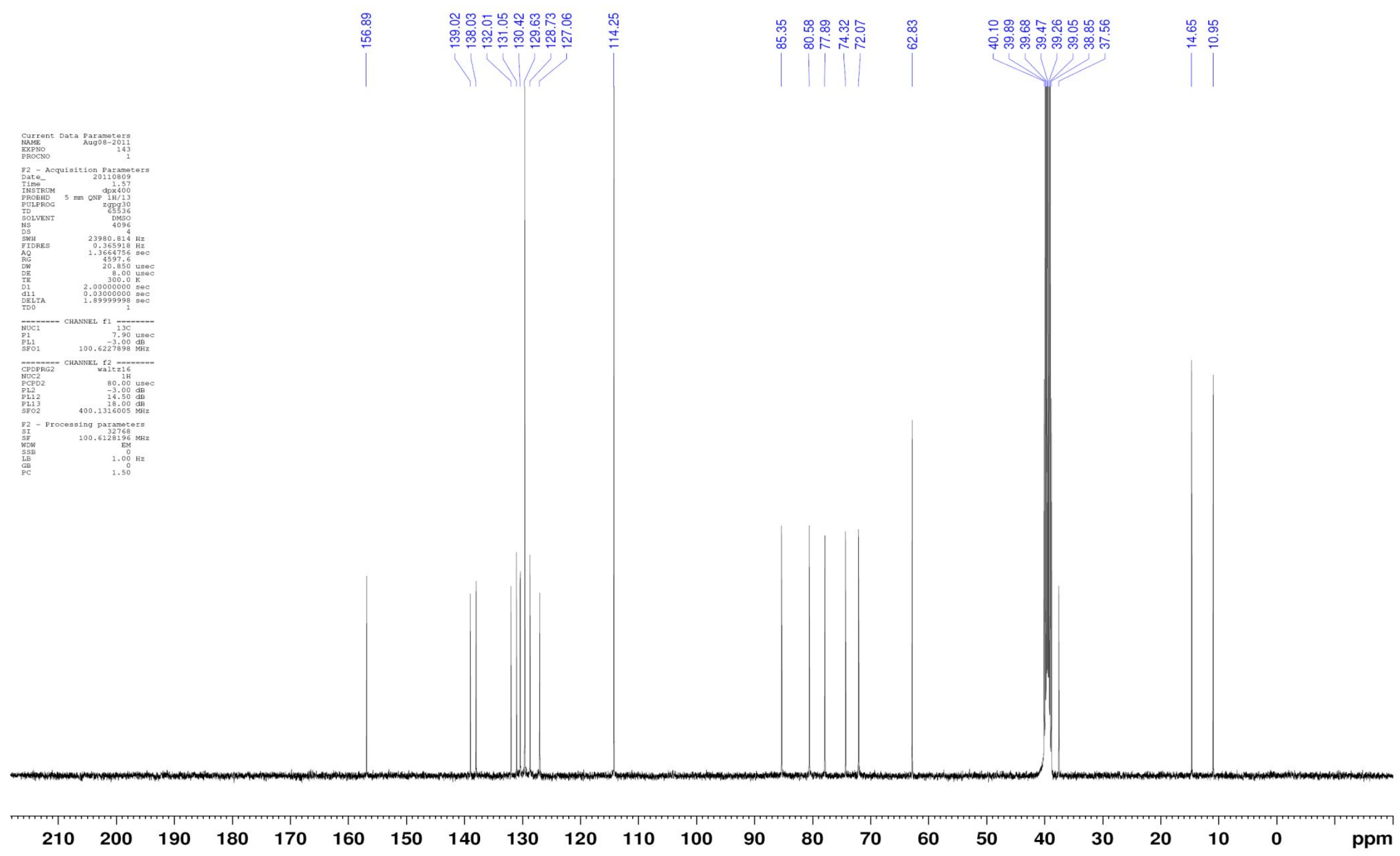


Figure S26. Single crystal X-ray crystallography of sotagliflozin methanol solvate

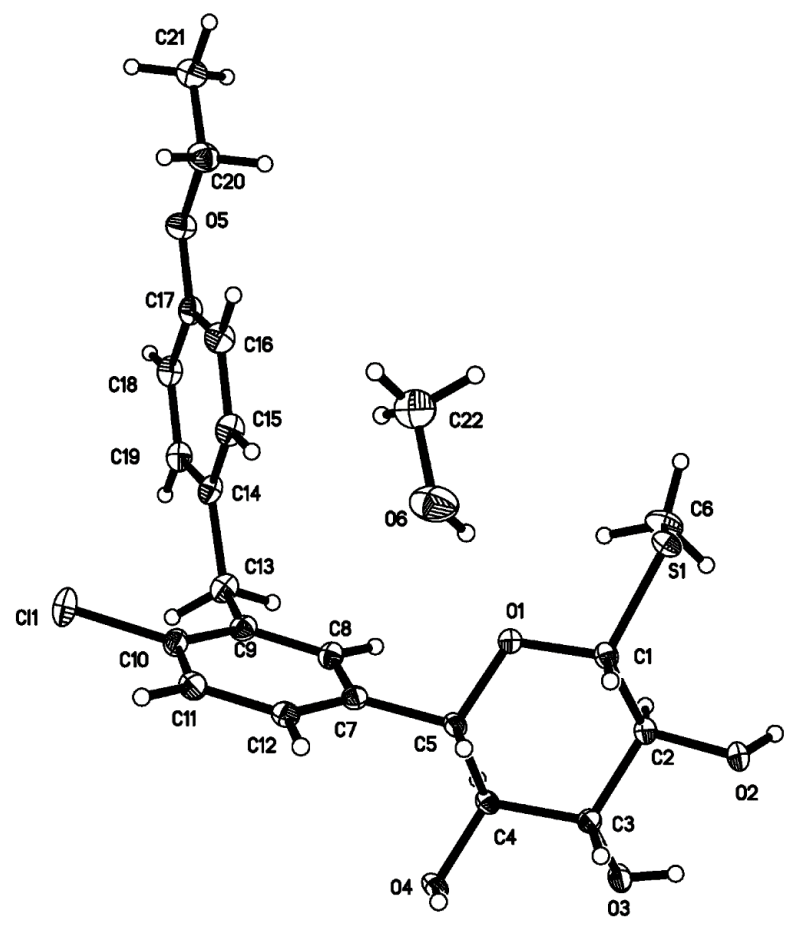

Note: Anisotropic atomic displacement ellipsoids for the non-hydrogen atoms are shown at the $50 \%$ probability level.

Hydrogen atoms are displayed with an arbitrarily small radius

Table S2. Crystal data of sotagliflozin methanol solvate

\begin{tabular}{|l|l|}
\hline Empirical formula & $\mathrm{C}_{22} \mathrm{H}_{29} \mathrm{ClO}_{6} \mathrm{~S}$ \\
\hline Formula weight & 456.98 \\
\hline Temperature & $100(2) \mathrm{K}$ \\
\hline Wavelength & $1.5418 \AA$ \\
\hline Crystal size & $0.25 \times 0.25 \times 0.10 \mathrm{~mm}$ \\
\hline Crystal habit & Colourless Block \\
\hline Crystal system & Orthorhombic \\
\hline Space group & $\mathrm{P} 2_{1} 22_{1}$ \\
\hline Unit cell dimensions & $\begin{array}{l}\mathrm{a}=5.4981(2) \AA \\
\mathrm{b}=8.9732(4) \\
\mathrm{c}=44.5335(17) \AA\end{array}$ \\
\hline Volume & $2197.08(15) \AA 3$ \\
\hline Z & 4 \\
\hline Density (calculated) & $1.381 \mathrm{Mg}^{3}$ \\
\hline Absorption coefficient & $2.736 \mathrm{~mm}^{-1}$ \\
\hline F(000) & 968 \\
\hline
\end{tabular}




\section{PREPARATION OF IMPURITIES}

2.1 Preparation of disulfide dimer impurities $(\mathbf{2 5}, \mathbf{2 5 a})$

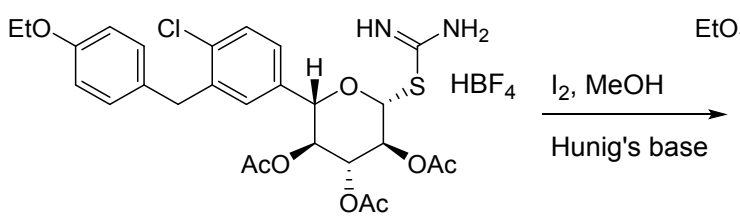

23

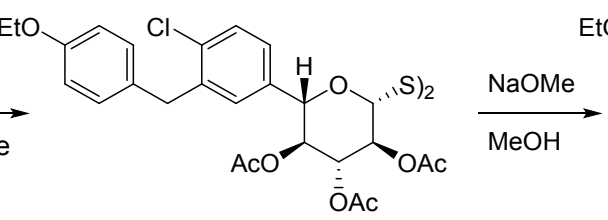

25

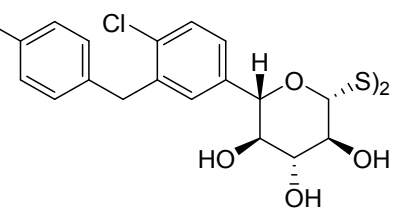

$25 a$

To a suspension of isothiourea $23(18.75 \mathrm{~g}, 28.2 \mathrm{mmol})$ in $\mathrm{MeOH}(112 \mathrm{~mL})$ was added $\mathrm{I}_{2}(7.52 \mathrm{~g}, 29.6$ mmol, 1.05 equiv). After stirring for 5 minutes, $i$ - $\operatorname{Pr}_{2} \mathrm{NEt}(14.7 \mathrm{~mL}, 84.6 \mathrm{mmol}, 3.0$ equiv) was added (exothermic, temperature rose from 22 to $33{ }^{\circ} \mathrm{C}$ ). The mixture was aged at $22{ }^{\circ} \mathrm{C}$ and more $\mathrm{I}_{2}(3.7 \mathrm{~g}, 0.5$ equiv) and $i-\operatorname{Pr}_{2} \mathrm{NEt}\left(5 \mathrm{~mL}, 1.0\right.$ equiv) were added. The mixture was aged at $22{ }^{\circ} \mathrm{C}$, concentrated to a low volume, and flushed with $\mathrm{MeOH}$ to give a thick slurry. DCM $(\sim 50 \mathrm{~mL})$ was added and the mixture slowly concentrated under a slight vacuum to remove most of the DCM with a final weight of $102 \mathrm{~g}$. The suspension was slowly cooled to $22^{\circ} \mathrm{C}$, aged for $2 \mathrm{~h}$ and filtered. The filter cake was washed with $\mathrm{MeOH}$ $(\sim 140 \mathrm{~mL})$ and dried in flowing air over the weekend to afford disulfide dimer acetate $25(9.23 \mathrm{~g}, 61 \%$ yield, 99.6\% purity). LC-MS: m/z 1088.8, calcd for $\left[\mathrm{M}+\mathrm{NH}_{4}\right]^{+} 1088.3$.

To a suspension of 25 (7.58 g, $7.07 \mathrm{mmol})$ in $\mathrm{MeOH}(49 \mathrm{~mL})$ was added $\mathrm{NaOMe}(25 \mathrm{w} \%$ in $\mathrm{MeOH}, 1.6$ $\mathrm{mL}, 0.9$ equiv). The mixture was warmed to $40{ }^{\circ} \mathrm{C}$ to give a clear solution in $15 \mathrm{~min}$. It was cooled to 22 ${ }^{\circ} \mathrm{C}$ over $1 \mathrm{~h}$ and quenched with water $(100 \mathrm{~mL})$. MTBE $(80 \mathrm{~mL})$ was added and the organic layer washed with water $(49 \mathrm{~mL})$. Attempted crystallization by adding antisolvent $\mathrm{n}$-heptane $(40 \mathrm{~mL})$ resulted in oiling out of the product. The mixture was concentrated to dryness at $50{ }^{\circ} \mathrm{C}$ to give $6.31 \mathrm{~g}$ of $\mathbf{2 5 a}$ as a foamy solid. LC-MS m/z 836.5, calcd for $\left[\mathrm{M}+\mathrm{NH}_{4}\right]^{+} 836.2$. ${ }^{1} \mathrm{H}$ NMR showed the presence of $16 \mathrm{~mol} \%$ residual MTBE $(1.7 \mathrm{w} \%)$. 
Figure S27. $\quad{ }^{1} \mathrm{H}$ NMR spectrum of disulfide dimer acetate $25\left(\mathrm{CDCl}_{3}\right)$

\section{NB-726-107-air-dry LC4211 S-S dimer}

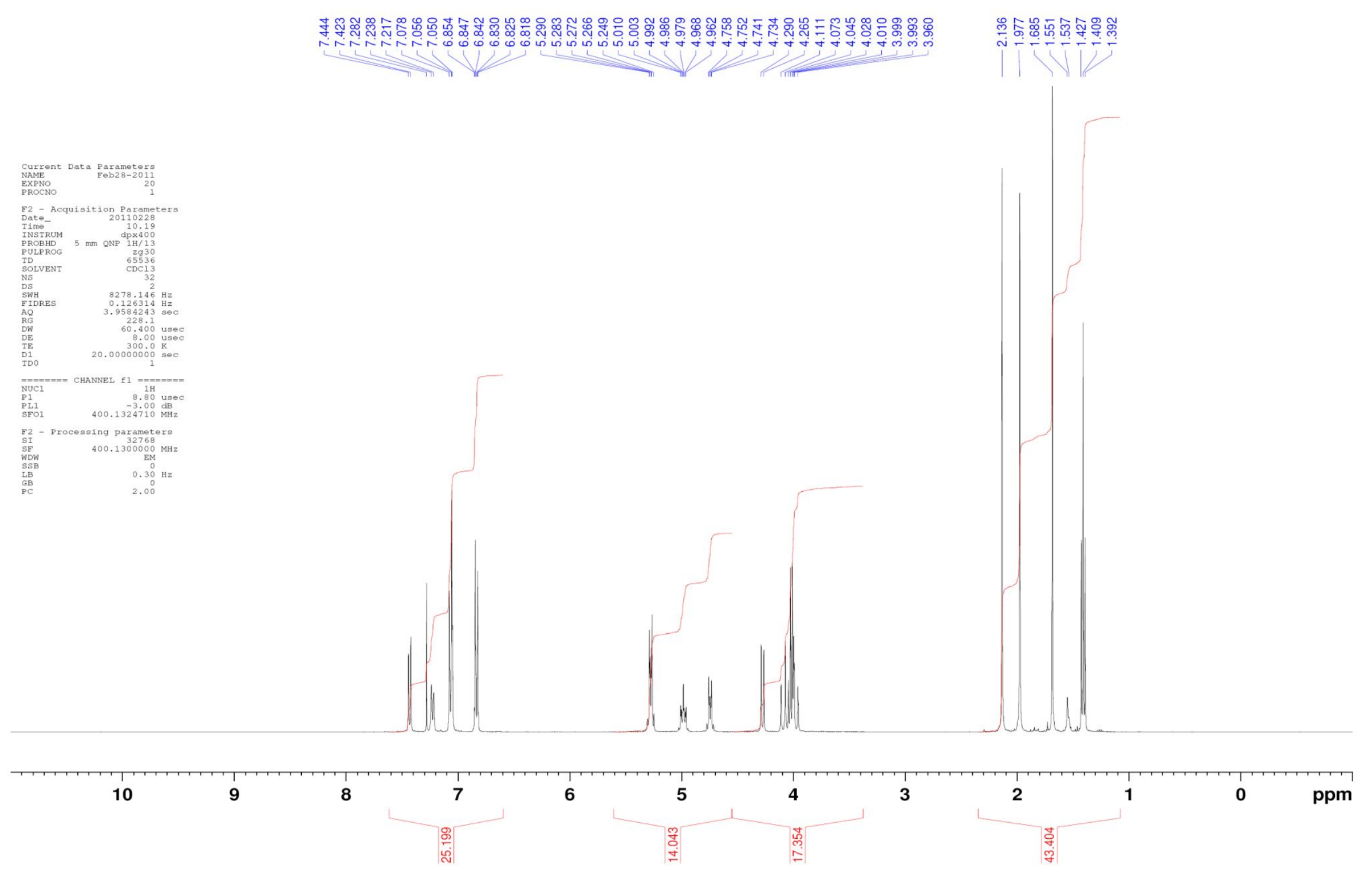


Figure S28. $\quad{ }^{13} \mathrm{C}$ NMR spectrum of disulfide dimer acetate $25\left(\mathrm{CDCl}_{3}\right)$

NB-726-107-air-dry LC4211 S-S dimer

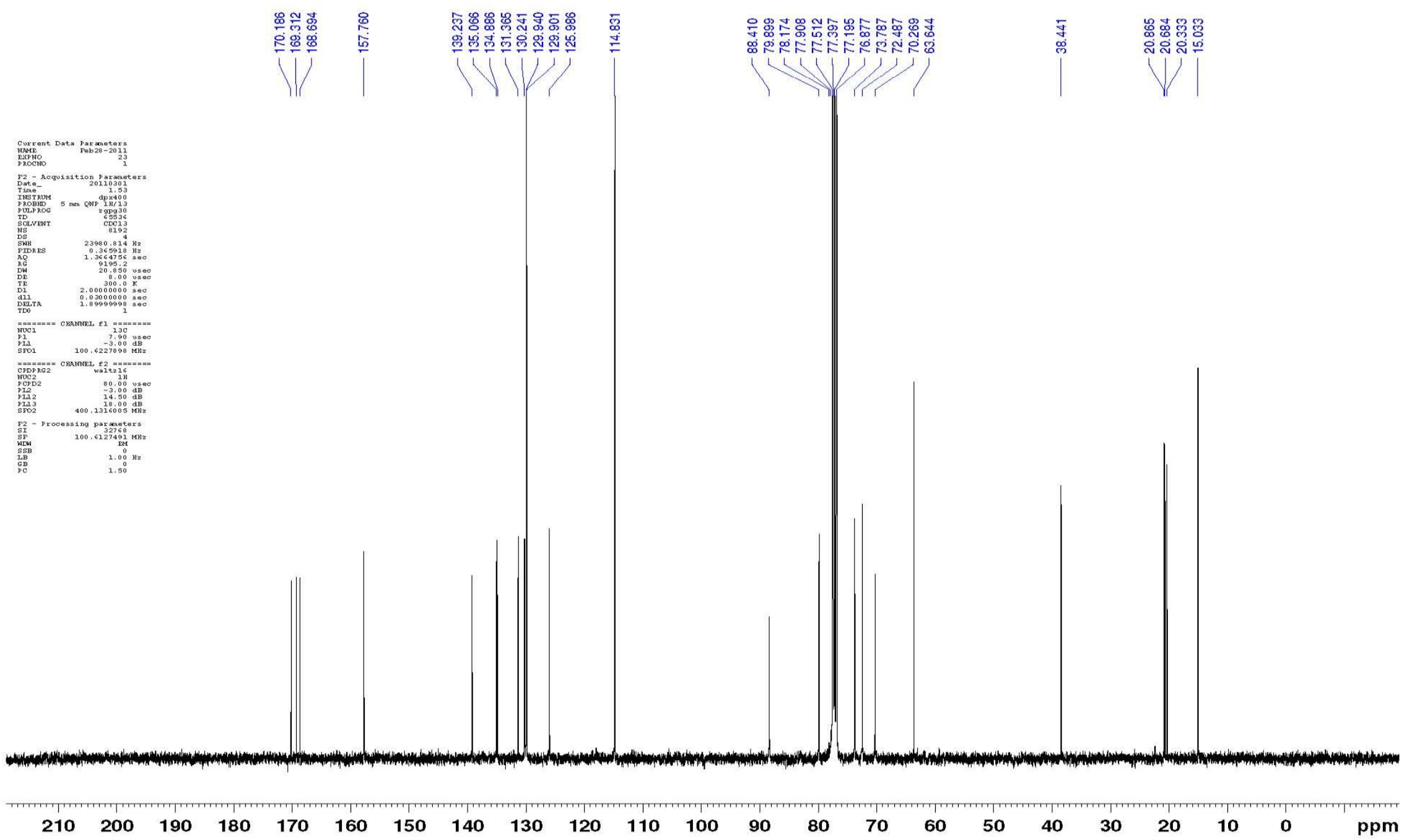


Figure S29. $\quad{ }^{1} \mathrm{H}$ NMR spectrum of disulfide dimer 25a (methanol- $\left.\mathrm{d}_{4}\right)$

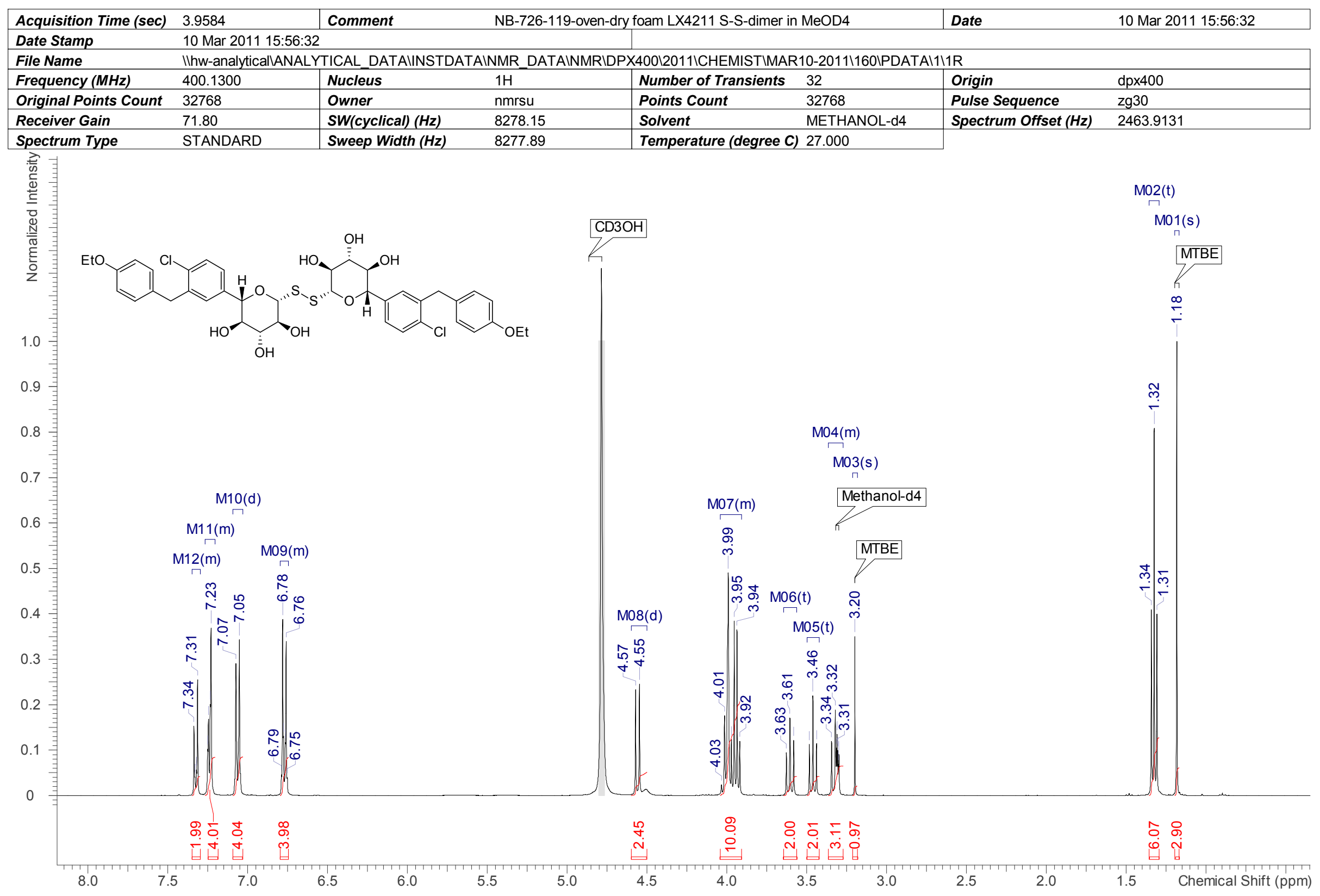


Figure S30. $\quad{ }^{13} \mathrm{C}$ NMR spectrum of disulfide dimer 25a (methanol-d $\mathrm{d}_{4}$ )

\section{NB-726-119-oven-dry foam LX4211 S-S-dimer in MeOD4}

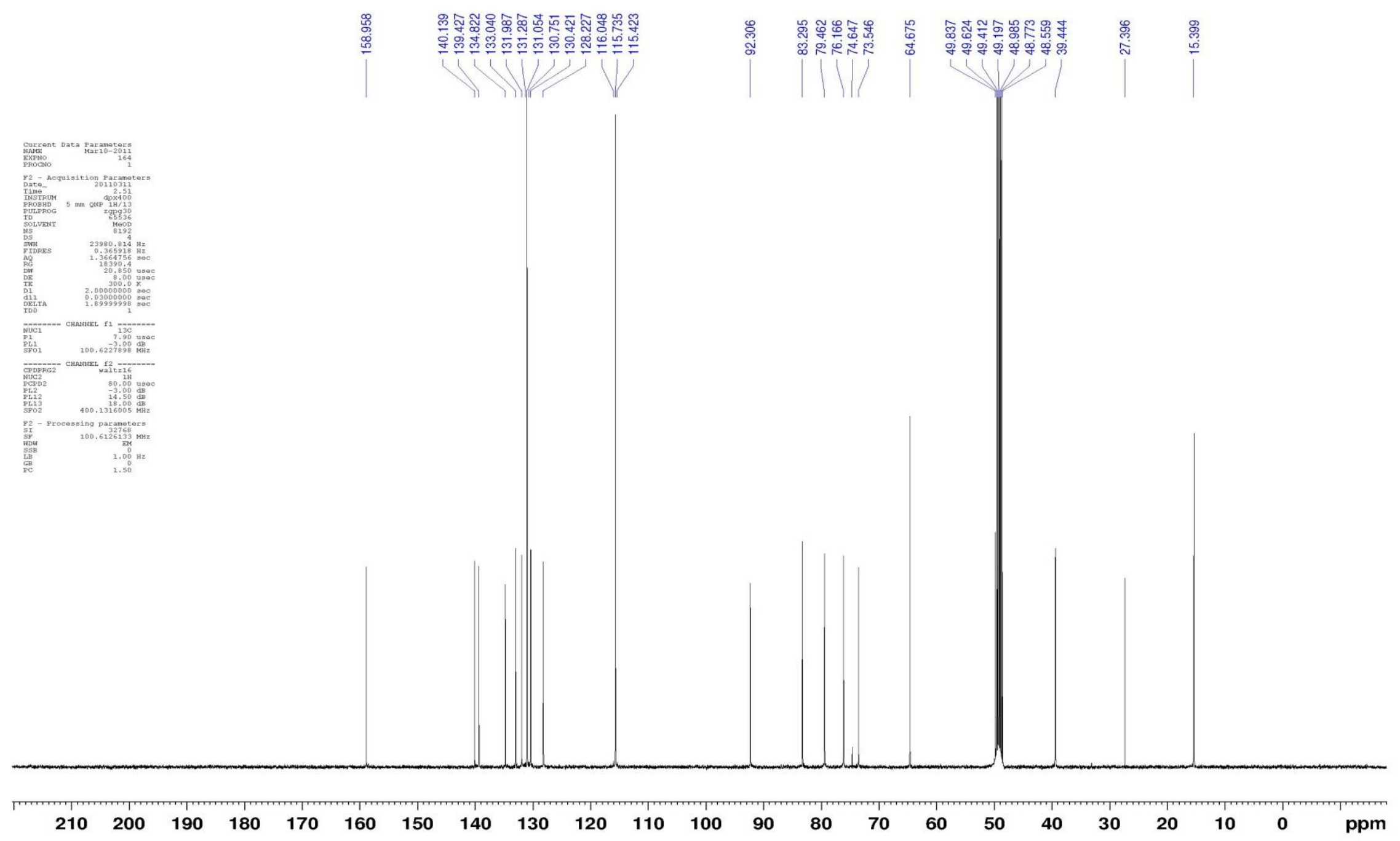


2.2 Preparation of methylene bridged dimer impurities $(\mathbf{4 0 , 4 0 a )}$

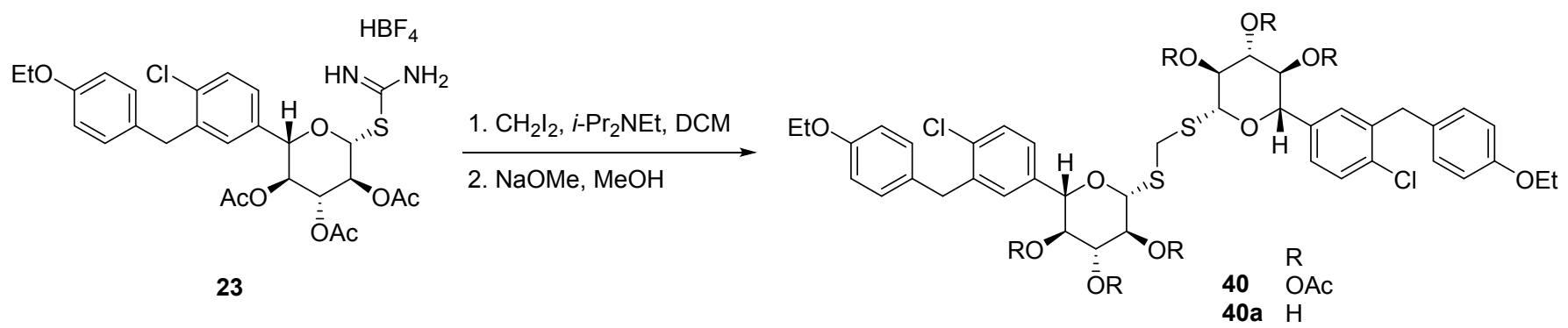

To a suspension of isothiourea 23 (18.68 g, $28.1 \mathrm{mmol})$ in DCM (75 mL, 4V) and MeOH (37 mL, 2V) was added $\mathrm{CH}_{2} \mathrm{I}_{2}$ (3.77 g, $12.1 \mathrm{mmol}, 0.50$ equiv) followed by $i$ - $\operatorname{Pr}_{2} \mathrm{NEt}$ (14.7 mL, $84.6 \mathrm{mmol}, 3.0$ equiv) at 22 ${ }^{\circ} \mathrm{C}$. The reaction mixture was aged at $22-25{ }^{\circ} \mathrm{C}$, concentrated to a low volume, and flushed with $\mathrm{MeOH}$ to give a thick suspension. DCM $(\sim 10 \mathrm{~mL})$ and $\mathrm{MeOH}(50 \mathrm{~mL})$ were added and the mixture was concentrated slowly and flushed with $\mathrm{MeOH}(100 \mathrm{~mL})$ with a final weight of $75.6 \mathrm{~g}$. After aging at $50{ }^{\circ} \mathrm{C}$ for $1 \mathrm{~h}$, it was cooled to rt, aged for $2 \mathrm{~h}$ and filtered. The filter-cake was washed sequentially with $\mathrm{MeOH}(70 \mathrm{~mL})$, water $(60 \mathrm{~mL} \times 3)$ and dried in flowing air to give $99.2 \%$ purity methylene bridged dimer 40 (13.16 g, 86\% yield) as a white solid. LC-MS m/z 1102.7, calcd for $\left[\mathrm{M}+\mathrm{NH}_{4}\right]^{+} 1102.3$.

To a suspension of 40 (11.0 g, $11.2 \mathrm{mmol})$ in $\mathrm{MeOH}(66 \mathrm{~mL})$ was added $\mathrm{NaOMe}(25 \mathrm{w} \%$ in $\mathrm{MeOH}, 2.2$ $\mathrm{mL}, 9.6 \mathrm{mmol}, 0.95$ equiv) at $\mathrm{rt}$. The mixture was aged at $\mathrm{rt}$ for $4 \mathrm{~h}$ to give a clear solution. Attempted crystallization by slowly adding water $(48 \mathrm{~mL})$ led to oiled/gummed out. After adding $\mathrm{MeOH}(44 \mathrm{~mL})$ age at $40{ }^{\circ} \mathrm{C}$ for $2 \mathrm{~h}$, the product eventually crystallized. The suspension was aged at $40{ }^{\circ} \mathrm{C}$ for $2 \mathrm{~h}$ cooled to 22 ${ }^{\circ} \mathrm{C}$ and aged. The product was filtered, washed with $\mathrm{MeOH} /$ water $(45 / 30 \mathrm{~mL})$ and dried in flowing air to give 40a as a white solid (8.16 g, 96.4\% yield, 99.5\% purity). LC-MS m/z 850.5; calcd for [M $\left.+\mathrm{NH}_{4}\right]^{+}$ 850.2 . 
Figure S31. $\quad{ }^{1} \mathrm{H}$ NMR spectrum of methylene bridged dimer acetate $40\left(\right.$ DMSO- $\left.\mathrm{d}_{6}\right)$

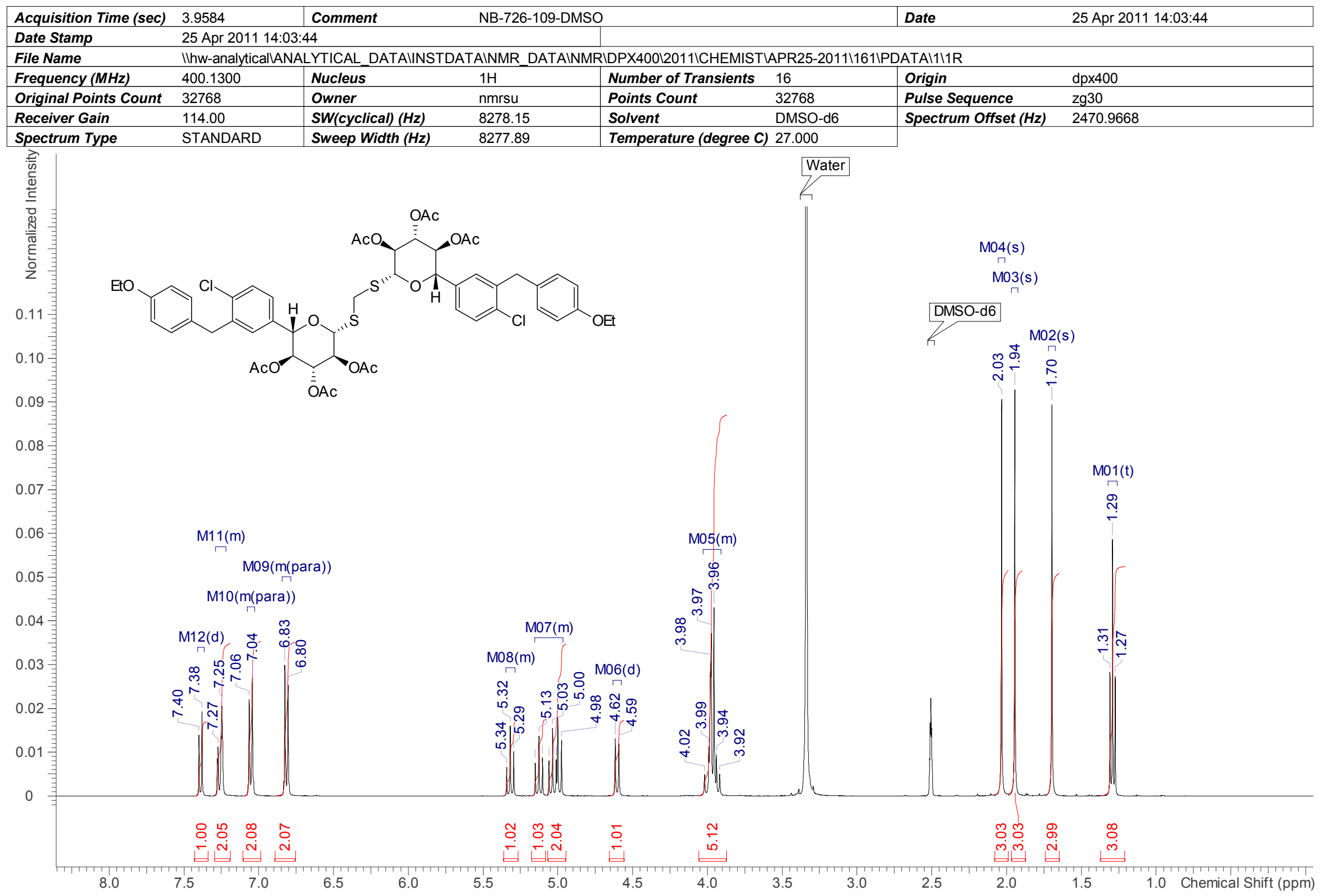


Figure S32 ${ }^{13} \mathrm{C}$ NMR of methylene bridged dimer acetate $40\left(\mathrm{CDCl}_{3}\right)$

NB-726-109-air-dry LX4211 methylene dimer

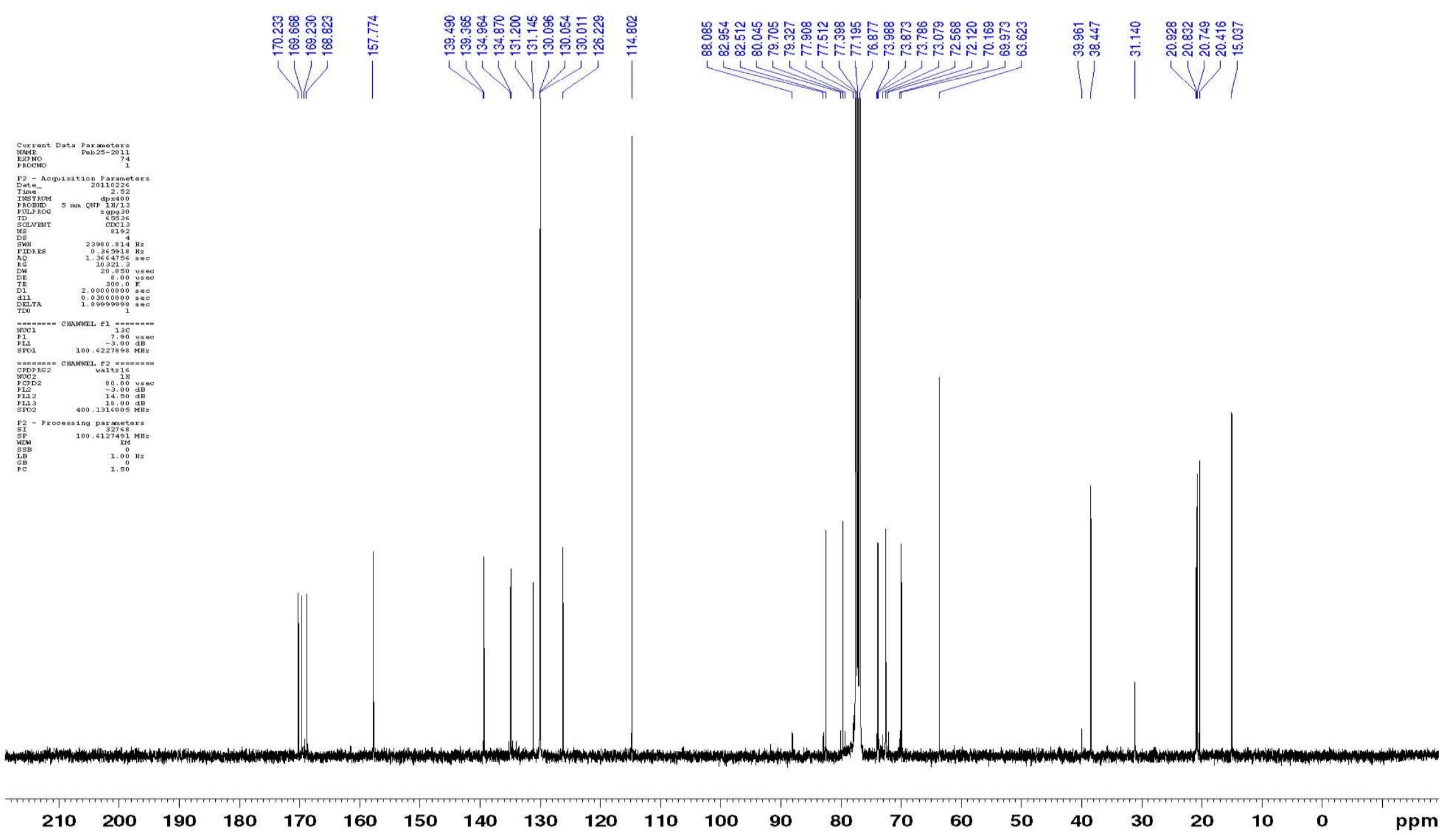


Figure S33 $\quad{ }^{1} \mathrm{H}$ NMR of methylene bridged dimer 40a (DMSO- $\mathrm{d}_{6}$ )

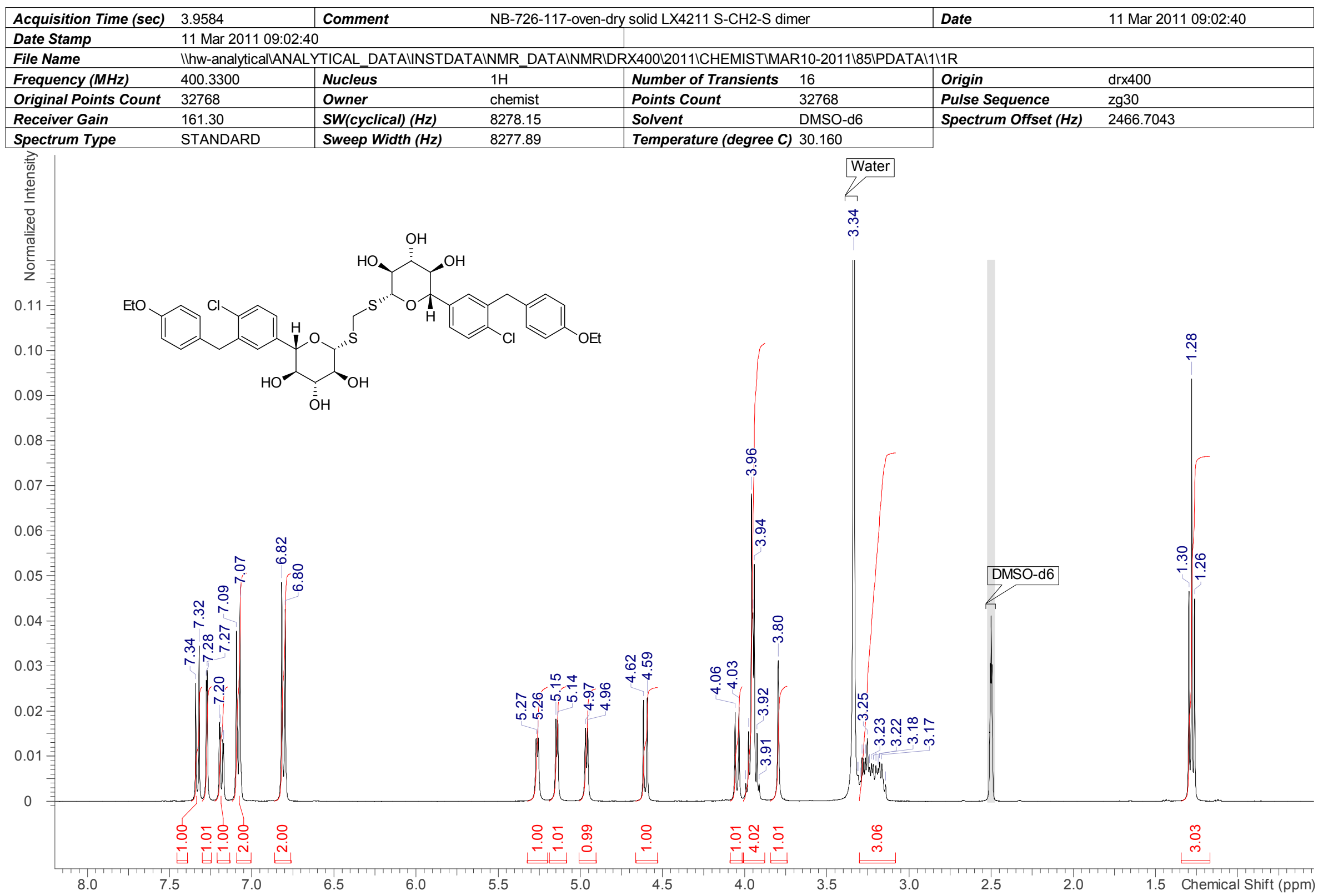


Figure S34 ${ }^{13} \mathrm{C}$ NMR of methylene bridged dimer 40a (DMSO- $\mathrm{d}_{6}$ )

NB-726-117-oven-dry solid LX4211 S-CH2-S dimer

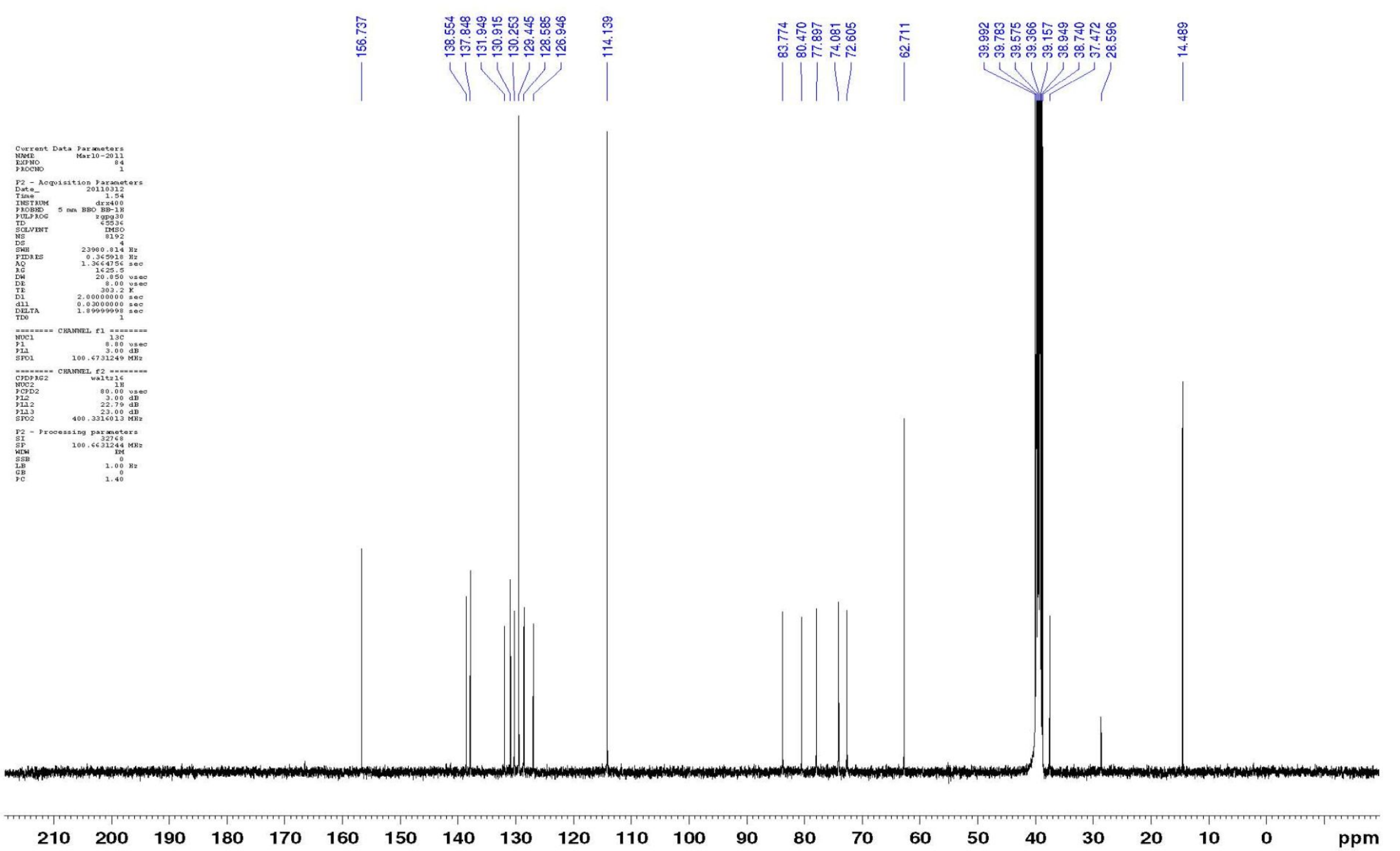

